\title{
Links between Large-Scale Modes of Climate Variability and Synoptic Weather Patterns in the Southern Indian Ocean $\mathscr{O}$
}

\author{
Danielle G. Udy, ${ }^{\mathrm{a}, \mathrm{b}}$ Tessa R. Vance, ${ }^{\mathrm{c}}$ Anthony S. Kiem, ${ }^{\mathrm{d}}$ NeIl J. Holbrook,${ }^{\mathrm{a}, \mathrm{b}}$ And Mark A. J. Curran ${ }^{\mathrm{e}, \mathrm{c}}$ \\ ${ }^{a}$ Institute for Marine and Antarctic Studies, University of Tasmania, Hobart, Tasmania, Australia \\ ${ }^{\mathrm{b}}$ ARC Centre of Excellence for Climate Extremes, University of Tasmania, Hobart, Tasmania, Australia \\ ${ }^{\mathrm{c}}$ Australian Antarctic Program Partnership, Institute for Marine and Antarctic Studies, University of Tasmania, \\ Hobart, Tasmania, Australia \\ ${ }^{\mathrm{d}}$ Centre for Water, Climate and Land, Faculty of Science, University of Newcastle, Callaghan, New South Wales, Australia \\ ${ }^{\mathrm{e}}$ Australian Antarctic Division, Kingston, Tasmania, Australia
}

(Manuscript received 26 April 2020, in final form 23 September 2020)

\begin{abstract}
Weather systems in the southern Indian Ocean (SIO) drive synoptic-scale precipitation variability in East Antarctica and southern Australia. Improved understanding of these dynamical linkages is beneficial to diagnose long-term climate changes from climate proxy records as well as informing regional weather and climate forecasts. Self-organizing maps (SOMs) are used to group daily 500-hPa geopotential height (z500; ERA-Interim) anomalies into nine regional synoptic types based on their dominant patterns over the SIO $\left(30^{\circ}-75^{\circ} \mathrm{S}, 40^{\circ}-180^{\circ} \mathrm{E}\right)$ from January 1979 to October 2018. The pattern anomalies represented include four meridional, three mixed meridional-zonal, one zonal, and one transitional node. The frequency of the meridional nodes shows limited association with the phase of the southern annular mode (SAM), especially during September-November. The zonal and mixed patterns were nevertheless strongly and significantly correlated with SAM, although the regional synoptic representation of SAM+ conditions was not zonally symmetric and was represented by three separate nodes. We recommend consideration of how different synoptic conditions vary the atmospheric representation of SAM + in any given season in the SIO. These different types of SAM + mean a hemispheric index fails to capture the regional variability in surface weather conditions that is primarily driven by the synoptic variability rather than the absolute polarity of the SAM.
\end{abstract}

KEYWORDS: Synoptic climatology; Interannual variability; Antarctic Oscillation; Blocking; Extratropical cyclones; Neural networks

\section{Introduction}

The southern Indian Ocean (SIO) region has the highest rates of cyclogenesis and cyclone density in the Southern Ocean (Simmonds et al. 2003). These extratropical cyclones, associated fronts, and warm conveyer belts travel in an eastward direction as part of the Antarctic circumpolar trough and are a major contributor to precipitation variability and extremes across southern Australia and East Antarctica (Uotila et al. 2011; Catto et al. 2015). However, their eastward propagation is frequently interrupted by periods of atmospheric blocking (Coughlan 1983; Renwick 2005), where a high pressure system remains approximately stationary for at least 6 days, splitting the westerly flow into two branches (Wright 1974). Blocks over the Tasman Sea (southeast of Australia) deflect cyclones south over East Antarctica and north over southern Australia, leading to a significant meridional redistribution of precipitation and the transportation of warm, moist air masses from the midlatitudes to inland Antarctica

Supplemental information related to this paper is available at the Journals Online website: https://doi.org/10.1175/JCLI-D-200297.s1.

Corresponding author: Danielle G. Udy, danielle.udy@utas. edu.au
(Massom et al. 2004; Pook et al. 2006, 2012; Scarchilli et al. 2011). Without the blocking mechanism, cyclones associated with coastal Antarctic precipitation rarely penetrate inland due to insufficient kinetic energy to pass over the steep coastal topography (King and Turner 1997; Walsh et al. 2000; Scarchilli et al. 2011). The presence of the steep coastal topography also strongly suppresses baroclinicity, which limits cyclonic activity over the Antarctic continent (Walsh et al. 2000). Over southern Australia, the approaching extratropical cyclone can also be "cut off" by the atmospheric block and travel equatorward. Such cutoff lows are associated with moderate to heavy precipitation across southern Australia (Hopkins and Holland 1997; Qi et al. 1999; Pook et al. 2006), contributing over $40 \%$ of the rainfall in southwest and southeast Australia during MAM and SON (Pook et al. 2012).

Variability in synoptic-scale processes and associated precipitation in the midlatitudes have implications for water security over southern Australia. For example, both the declining trend in precipitation over southwestern Australia since the late 1970s (Hope et al. 2006; Frederiksen and Frederiksen 2007) and the Millennium Drought (1997 to 2010) in southeast Australia (Murphy and Timbal 2008; Verdon-Kidd and Kiem 2009; Kiem and Verdon-Kidd 2010; Verdon-Kidd et al. 2014) have been linked to decreased baroclinicity in the midlatitudes (Frederiksen et al. 2017). This has been associated with a southward shift in the midlatitude storm tracks and subtropical ridge (Frederiksen and Frederiksen 2007; Rudeva 
et al. 2019) and poleward expansion of the SH Hadley cell (Nguyen et al. 2015). These trends also coincide with increases in atmospheric pressure over southern Australia and decreased pressure near the Antarctic coastline over the last three decades (Simmonds 2015).

There are currently limited observations and understanding of decadal variability of SIO synoptic systems, especially prior to the satellite period (i.e., pre-1979). Information derived from climate-sensitive, very high-resolution paleoclimate proxies like ice cores provides a valuable opportunity to reconstruct the long-term variability of synoptic processes prior to observational records (McMorrow et al. 2004; van Ommen and Morgan 2010). However, limited understanding of how the variability of SIO synoptic processes (daily to decadal) are preserved in East Antarctic ice cores limits their interpretation and application (McMorrow et al. 2004). At coastal ice core sites in East Antarctica, event-scale precipitation and redistribution of surface snow can enhance or weaken proxy links to regional climate processes (McMorrow et al. 2004; Scarchilli et al. 2011). Identifying SIO synoptic-scale processes will assist in the physical and dynamic interpretation of East Antarctic ice core proxy signals of climate and large-scale modes of variability.

Numerous studies of synoptic weather in the Southern Ocean/Antarctica exist, yet most focus on climatologies or case studies of individual features such as extratropical cyclones (Simmonds and Keay 2000; Pezza et al. 2008; Uotila et al. 2011; Catto et al. 2015), anticyclones/blocking (Jones and Simmonds 1994; Pook 1994; Sinclair 1996; Pezza and Ambrizzi 2003; Liu et al. 2018; Pepler et al. 2019b), or back trajectory studies of air parcels associated with snowfall near ice core sites (Reijmer et al. 2002; Scarchilli et al. 2011). These studies have generally been undertaken over shorter time periods and with reanalysis products of lower resolution than what is currently available. Synoptic-typing studies of the full Antarctic and Southern Ocean domain (Lynch et al. 2006; Pohl and Fauchereau 2012) are dominated by variability in specific quasi-annual low and high SLP regions (Amundsen Sea low and southeast Pacific anticyclone) and shifts in the location of the anticyclone over the Antarctic continent. They are thus of limited use in understanding synoptic variability in the SIO and signal preservation in East Antarctic ice cores.

This study contributes to the ultimate aim of understanding synoptic-scale signal preservation in coastal East Antarctic ice cores, through a regional climatological study (January 1979_ October 2018) of daily synoptic types. Synoptic climatological approaches can be used to characterize regional climate processes by reducing the dimension of the input data while retaining important information on the daily processes often lost by monthly or seasonal mean fields (Barry and Perry 2001). These approaches allow for key daily weather patterns to be grouped based on similar features to provide a dataset for investigating frequency of occurrence, associated surface conditions, and representation of physical and chemical proxies analyzed in East Antarctic ice cores (e.g., Vance et al. 2013, 2015, 2016) and their application to studies of climate risk (e.g., Tozer et al. 2018; Armstrong et al. 2020; Kiem et al. 2020). This study focuses on the physical descriptions of the key regional synoptic weather types of the SIO, their frequency of occurrence, and links to large-scale modes of climate variability. This study also provides a dataset of daily synoptic classifications for future studies of climate variability in the SIO region.

\section{Climate variability in the southern Indian Ocean}

Large-scale modes of climate variability known to influence the SIO study region include the southern annular mode (SAM; Marshall 2003), El Niño-Southern Oscillation (ENSO; McPhaden et al. 2006), and the Indian Ocean dipole (IOD; Saji et al. 1999). The SAM represents the leading mode of SH atmospheric variability and is principally zonally symmetric (annular) in structure (Thompson and Wallace 2000; Marshall 2003). However zonal asymmetries south of $50^{\circ} \mathrm{S}$ occur (particularly in JJA) in the southwest Atlantic, Indian, and southwest Pacific Oceans (Kidston et al. 2009; Pezza et al. 2012). This asymmetric pattern is reflected in planetary wave activity, particularly wavenumbers 1 and 3, and displays the largest amplitude in the South Pacific (Pezza et al. 2012; Irving and Simmonds 2015). This region is located at the poleward end of the Pacific-South American (PSA) anomaly pattern and is teleconnected to tropical Pacific variability (e.g., ENSO) through atmospheric Rossby wave propagation (e.g., Hoskins and Karoly 1981). As such, the influence of ENSO on Antarctic climate is strongest in West Antarctica and affects local climate such as temperature and moisture advection, and the behavior of synoptic weather patterns through changes in local baroclinicity and winds (Peng and Whitaker 1999; Turner 2004; Irving and Simmonds 2016; Turner et al. 2017; Yuan et al. 2018). The strength of this teleconnection between the tropical Pacific and West Antarctica is modulated by the phase of SAM, with in-phase (out-of-phase) circulation anomalies supporting (reducing) the transfer of ENSO anomalies to high latitudes (Fogt et al. 2011). The influence of ENSO and PSA on climate variability in East Antarctica is weaker but still significant compared to the climatological mean (e.g., Irving and Simmonds 2016; Marshall and Thompson 2016; Marshall et al. 2017).

Synoptic weather patterns characterized by positive geopotential height anomalies over Antarctica and negative anomalies over the midlatitudes (southern Australia) are expected to be associated with negative SAM (SAM-) conditions (Thompson and Wallace 2000; Marshall 2003) and potentially El Niño conditions (Yang et al. 2020) as these two phases of SAM and ENSO often co-occur (Fogt et al. 2011; Dätwyler et al. 2020). In the SIO, these conditions reflect an equatorward shift in the polar jet leading to an increased chance of fronts and extratropical cyclone activity in the midlatitudes (Rudeva and Simmonds 2015; Yang et al. 2020). Synoptic types representing a poleward displacement of the storm track in the SIO are expected to be associated with positive SAM (SAM+) conditions, with increased anticyclonic breaking on the equatorward side of the polar jet (Spensberger et al. 2019). As SAM+ often co-occurs with La Niña (Fogt et al. 2011; Dätwyler et al. 2020), synoptic types that characterize storm-track poleward displacement may also be associated with La Niña conditions.

Signatures of the IOD have also been identified in Antarctic sea ice variability and regional circulation anomalies (Purich 


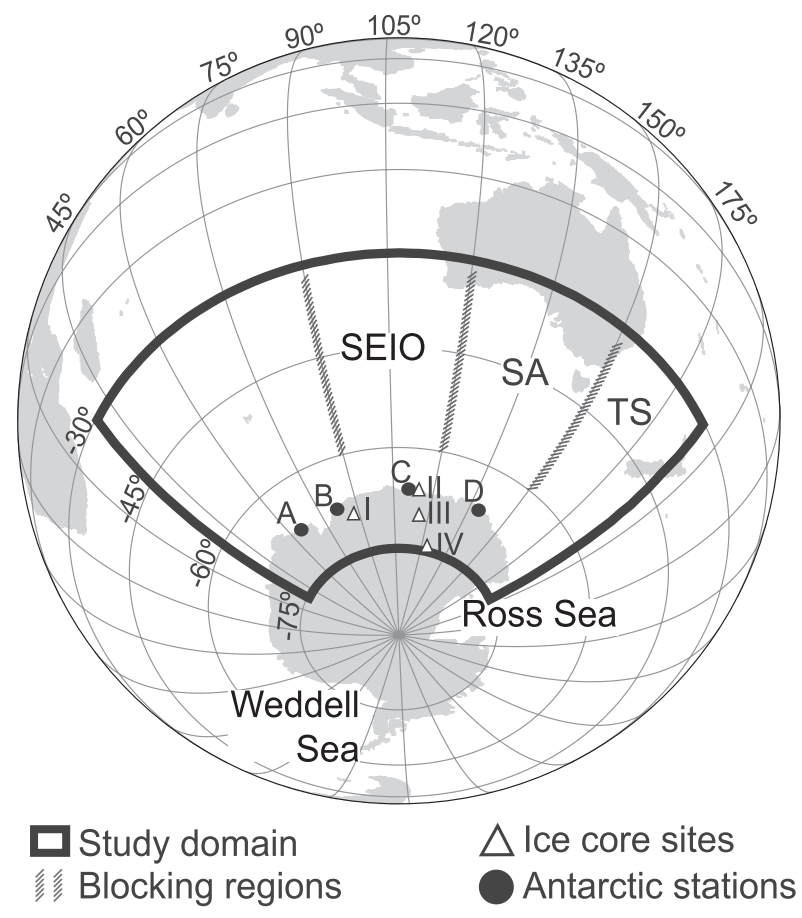

FIG. 1. Map of the southern Indian Ocean study domain. Relevant ice core locations (I: Mount Brown South (MBS); II: Law Dome; III: Aurora Basin North (ABN); and IV: Dome C), Antarctic stations (A: Mawson; B: Davis; C: Casey; and D: Dumont D'Urville) and blocking index regions (SEIO: Southeast Indian Ocean; SA: Southern Australia; TS: Tasman Sea) within the synoptic-typing domain are also indicated.

and England 2019; Wang et al. 2019). While the physical mechanisms for how and whether an Indian Ocean atmospheric Rossby wave train can propagate into the Southern Ocean have not been established, there does appear to be an "observed" wave train pattern (McIntosh and Hendon 2018). This observed continuous pattern has been suggested to be a combination of two separate Rossby wave train patterns, one from the tropical Indian Ocean and the other from high latitudes upstream of Australia (McIntosh and Hendon 2018). Investigating the dynamics of the IOD in relation to the synoptic types is beyond the scope of this study. However, based on this observed wave train anomaly pattern (Cai et al. 2011; McIntosh and Hendon 2018), synoptic types characterized by a positive (negative) height anomaly over southwestern Australia may have a statistical (not necessarily physical) link with positive (negative) IOD in SON.

\section{Data and methods}

\section{a. Study domain}

The SIO domain selected $\left(30^{\circ}-75^{\circ} \mathrm{S}, 40^{\circ}-180^{\circ} \mathrm{E}\right)$ represents the synoptic weather patterns influencing coastal regions over the East Antarctic ice sheet and southern Australia (Fig. 1). The study region encompasses the SIO and southwest Pacific
Ocean sector of the Southern Ocean and includes landmasses over coastal East Antarctica, southern Australia, and New Zealand. Two coastal East Antarctic ice cores sites-Law Dome, Dome Summit South $\left[66.77^{\circ} \mathrm{S}, 112.81^{\circ} \mathrm{E} ; 1370 \mathrm{~m}\right.$ above mean sea level (MSL)] and Mount Brown South $\left(69.11^{\circ} \mathrm{S}\right.$, $86.31^{\circ} \mathrm{E} ; 2078 \mathrm{~m} \mathrm{MSL}$ ) - are located within the study region. The northern and eastern boundaries of the domain slightly overlap with previous regional synoptic-typing studies, including those focused on southwest Australia (Hope et al. 2006), southeast Australia (Verdon-Kidd and Kiem 2009), New Zealand (Kidson 2000; Jiang et al. 2013), and the Ross Sea (Cohen et al. 2013). These overlaps were used as validation for checking pattern consistency between our study and those patterns in previous studies.

\section{b. Reanalysis climate data}

This study used the ERA-Interim $\left(0.75^{\circ} \times 0.75^{\circ}\right.$ grid $)($ Dee et al. 2011) 500-hPa geopotential height (z500) daily anomalies over the period from January 1979 to October 2018 to derive synoptic pressure patterns over the SIO region $\left(30^{\circ}-75^{\circ} \mathrm{S}\right.$, $40^{\circ}-180^{\circ} \mathrm{E}$ ) through self-organizing maps (SOMs). The ERAInterim dataset realistically represents pressure fields in both the Antarctic (Bracegirdle and Marshall 2012; Grieger et al. 2018) and Australian regions (Pepler et al. 2018, 2019a). ERA5 $\left(0.28^{\circ} \times 0.28^{\circ}\right.$ grid $)$ has recently become available; however, we used ERA-Interim as it has been previously evaluated as being realistically representative of the pressure fields in the SIO region and it is unlikely that large-scale analysis in this study is sensitive to reanalysis product resolution (Bracegirdle and Marshall 2012; Rohrer et al. 2020).

\section{c. Self-organizing map analysis}

The SOM algorithm within the "Kohonen" R-package (Wehrens and Kruisselbrink 2018) was used to identify key regional synoptic patterns in the study region. SOMs have been successfully used to analyze synoptic weather across multiple regions (e.g., Hope et al. 2006; Verdon-Kidd and Kiem 2009; Reusch 2010; Hosking et al. 2017) and have contributed to improved interpretation of West Antarctic ice core climate proxies (Reusch et al. 2005; Reusch 2010; Hosking et al. 2017).

Synoptic classification relies on the assumption that atmospheric patterns can be partitioned into a specified number of "types." The SOM algorithm is often preferred over traditional discrete clustering methods (e.g., $k$-means) as it accounts for continuity and nonlinearity (Jiang et al. 2012), providing a more realistic representation of the continuous movement between weather patterns rather than assigning to discrete clusters that may misrepresent extremes. The SOM algorithm achieves this by categorizing data more uniformly, preserving the probability density of the input data, as well as maintaining the topological order of the data by updating both the "winning" node and neighborhood node at each iteration (Hewitson and Crane 2002). These attributes make the SOM algorithm preferable when consideration of both extremes and average climatology is important (Hewitson and Crane 2002; Cassano et al. 2006). Refer to the methods sections of Cassano et al. (2006) and Verdon-Kidd and Kiem (2009) for SOM algorithm descriptions. 


\section{1) SOM INPUT AND PARAMETERS}

The SOM analysis was run at the daily time scale for both the z500 field and z500 anomalies for the period January 1979 to October 2018, with similar patterns observed between the two data inputs. The daily anomalies were selected as the results achieved improved Euclidean distance scores and provided clearer distinction between patterns. The sensitivity to pressure level and spatial resolution were also tested by running the SOM with mean SLP and weighted input vectors, respectively. The resulting mean SLP patterns were similar to the z500 results. However, the Euclidean distance scores and pattern correlation scores between each winning node and daily time step performed worse than the z500 results. The SOM output of synoptic-scale features was not sensitive to the grid size or weighting of the input vectors, with similar results observed between the native ERA-Interim grid (regular latitudelongitude grid) and weighted input vectors (square root of the cosine of latitude). The results presented here use the native ERA-Interim grid as the input vector. The following grid parameters were selected: rectangular topology, Gaussian neighborhood function, and Euclidean distance measurement. Training was carried out over 1000 iterations (improvement plateaued between 800 and 900 iterations), with the learning rate decreasing linearly from 0.05 to 0 . Consistent with previous studies (Gibson et al. 2017; Jiang et al. 2012, 2015), the SOM results were not overly sensitive to grid parameters or changes in learning rate. Similar to Gibson et al. (2017), the sensitivity to the end point of the neighborhood radius parameter was tested using two scenarios; traditional SOM (radius decrease linearly from 4 to 1 over iterations) and hybrid of SOM-clustering (radius decrease linearly from 4 to 0 over iterations). In the "Kohonen" $\mathrm{R}$-package, a radius value less than or equal to one corresponds to the point where only the winning node is updated by each iteration, making the SOM algorithm similar to clustering techniques (e.g., $k$-means). The output patterns were similar between the traditional SOM and hybrid SOMclustering runs. However, the hybrid SOM-clustering approach (75\% SOM, 25\% clustering) achieved improved Euclidean distance and Pearson pattern correlation scores, and so this approach was used for this study. Last, the size of the SOM grid has a strong influence on the range of synoptic patterns represented. The outputs of SOMs are generalized when fewer nodes are selected, and more specific with a wider range of patterns as the number of nodes increases. Multiple combinations of SOM node grids were tested to determine which best represented the synoptic situations of the region, including $2 \times 2(4), 3 \times 2(6), 3 \times 3(9)$, and $3 \times 4$ (12). The final size of the SOM grid $(3 \times 3$ nodes $)$ was selected based on visual inspection, performance score of the SOMs, and discussions with meteorologists working in the study region. Types representing deep low pressure systems near the Antarctic coast, extensive high pressure systems over southern Australia, and high pressure ridges extending to higher latitudes in the Tasman Sea were expected, along with the appropriate eastward progression of weather systems across the study domain.

\section{2) SOM EVALUATION}

To evaluate how realistic the SOM output was compared to actual daily synoptic patterns, we calculated the Pearson pattern correlation between each winning node (composite map) and the observed z500 at each daily time step [similar to Gibson et al. (2017)]. The overall accuracy of the output node patterns was quantified by analyzing the distribution of all daily pattern correlations within each SOM node (Fig. 2). Over $97 \%$ of the daily observations recorded a Pearson pattern correlation $>0.8$ with the assigned composite node pattern, with the remaining $3 \%$ achieving a correlation $>0.7$. This provided confidence that each winning node was representative of actual daily weather patterns in the study region.

\section{d. Climate variability and blocking indices}

Annual and seasonal correlations were calculated to investigate potential links between synoptic-type occurrence and modes of climate variability known to influence the study region, specifically SAM, ENSO, and the IOD. The indices used in this study were the monthly Marshall SAM index (Marshall 2003) [see review by Ho et al. (2012)], the monthly Southern Oscillation index (SOI; Troup 1965), Niño-4 SSTA, and the Oceanic Niño Index (ONI; 3-month running mean of SSTA in the Niño-3.4 region) and the monthly Dipole Mode Index (DMI) for IOD [refer to Verdon and Franks (2005) and Abram et al. $(2015,2020)$ for discussion around the use of DMI]. A combination of SLP (SOI) and SSTA (Niño-4 and ONI) based indices were selected to represent the phase and strength of ENSO events due to the western pole of the SOI (Darwin) often being influenced by the state of the Indian Ocean (Behera and Yamagata 2003). The Niño-4 SST region in the western Pacific is also more dynamically linked to eastern Australian rainfall (Wang and Hendon 2007).

Synoptic types were also compared to Australian region monthly blocking indices calculated from NCEP-NCAR reanalysis data (Kalnay et al. 1996) following the approach of Pook and Gibson (1999) for the Tasman Sea $\left(150^{\circ}-180^{\circ} \mathrm{E}\right)$, southern Australia $\left(120^{\circ}-150^{\circ} \mathrm{E}\right)$ and the SIO $\left(90^{\circ}-120^{\circ} \mathrm{E}\right)$ sectors. Blocking in these regions influences Australian rainfall (Risbey et al. 2009) and East Antarctic precipitation (Massom et al. 2004; Pook et al. 2006, 2012; Scarchilli et al. 2011; Servettaz et al. 2020).

Correlation analysis was performed over the period from June 1979 to May 2018 to achieve an even number of seasons over the 39-yr record and to capture the IOD and ENSO event peaks in a select year. Prior to correlation analysis, an annual and seasonal SOM frequency time series was calculated for each SOM node by counting each daily occurrence within a year (June-May) or season. The monthly climate mode/ blocking indices were averaged over the same time periods. The annual and seasonal SOM frequency, climate mode, and blocking time series were then detrended and tested for autocorrelation and normality (using the Shapiro-Wilkes test). No significant autocorrelation (lag-1) was detected; however, the time series were both normally distributed and positively skewed so we used Pearson and Spearman methods for correlation analysis. The correlation score and significance level 

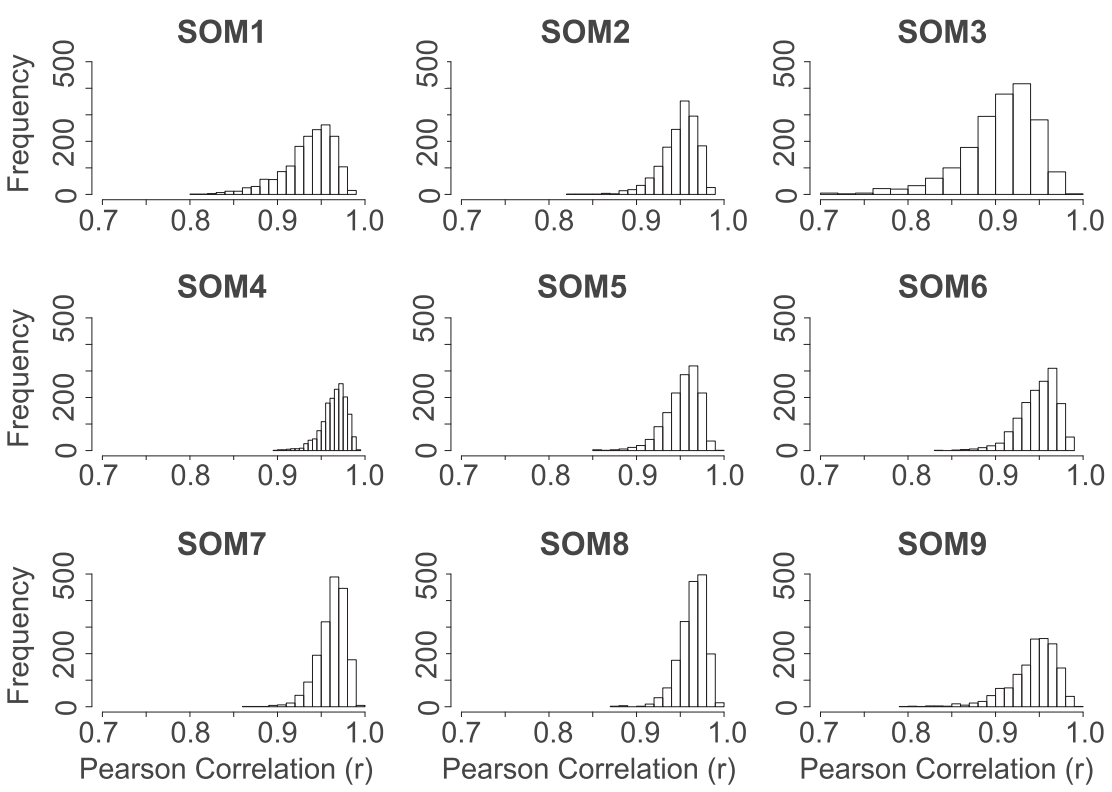

FIG. 2. Histogram of Pearson pattern correlation $(r)$ score between the winning SOM node composite and each daily time step assigned to each of the nine SOM nodes. Note the bar width varies for each histogram due to a fixed number of bars (15) used over the Pearson correlation range from 0.7 to 1.0 .

(two-sided Student's $t$ test for $p<0.05$ ) were generally consistent between the methods, with a few exceptions. The Spearman correlation results are presented here, and the Pearson correlation results are included as supplemental material.

\section{Results}

Nine regional synoptic types were identified based on the patterns and strength of weather systems in the study region (Figs. 3 and 4 ). The SOM output describes realistic synoptic conditions (Fig. 2) including distinct meridional patterns with anticyclonic ridging, zonal patterns, and mixed zonalmeridional patterns. The transition between these nodes is represented by SOM5. Given the nature of the method, similar types are nearer each other while opposite types are farther apart. For example, the anomaly patterns between SOM1 and SOM9 are opposite with the strong positive anomaly in the center of the domain in SOM1 replaced by a strong negative anomaly in SOM9.

Positive height anomalies are associated with ridges of high pressure extending poleward and negative height anomalies with low pressure systems and fronts. The structure of the negative anomalies in the SOM nodes is consistent with the Indian Ocean distribution of frontal systems (Rudeva and Simmonds 2015) and z500 cyclones (Keable et al. 2002). The patterns identified for this region are consistent with other synoptic-typing studies that include regions of overlap on the northern and eastern boundaries (Kidson 2000; Hope et al. 2006; Verdon-Kidd and Kiem 2009; Cohen et al. 2013; Jiang et al. 2013, 2015).

\section{a. Description of synoptic-type patterns and frequent transitions}

The key synoptic features (Fig. 3) and frequent transition patterns (Fig. 5) for the nine SOM nodes are described below. The synoptic types are grouped based on the key patterns, into meridional nodes (SOM1, SOM2, SOM6, and SOM9), mixed nodes (SOM4, SOM7, and SOM8), a zonal node (SOM3), and a transitional node (SOM5). The ordering of description within the meridional and mixed node groups is based on the most frequent transitions between the SOM nodes (Fig. 5). The transitions between nodes reflect the expected eastward progression of synoptic weather systems in the study region, consistent with Rossby wave propagation within the high-latitude (eddy-driven) jet (McIntosh and Hendon 2018).

\section{1) Meridional nODES}

\section{(i) SOM1-Positive anomaly at $55^{\circ} \mathrm{S}, 115^{\circ} \mathrm{E}$}

SOM1 is characterized by a strong positive height anomaly at $55^{\circ} \mathrm{S}, 115^{\circ} \mathrm{E}$, extending from southwest Australia to the Antarctic coastline near Casey Station in Wilkes Land. A positive height anomaly ridge also extends over inland Antarctica. Negative height anomalies, both extending from the midlatitudes $\left(\sim 35^{\circ} \mathrm{S}\right)$ to the East Antarctic coastline $\left(\sim 66^{\circ} \mathrm{S}\right)$, are located to the west (near Mawson Station) and east (near Dumont d'Urville station) of the positive height anomaly. SOM1 is persistent for at least two consecutive days for $7 \%$ of the analysis period, and predominantly transitions to SOM2. SOM7 is the most likely node to transition into SOM1. 

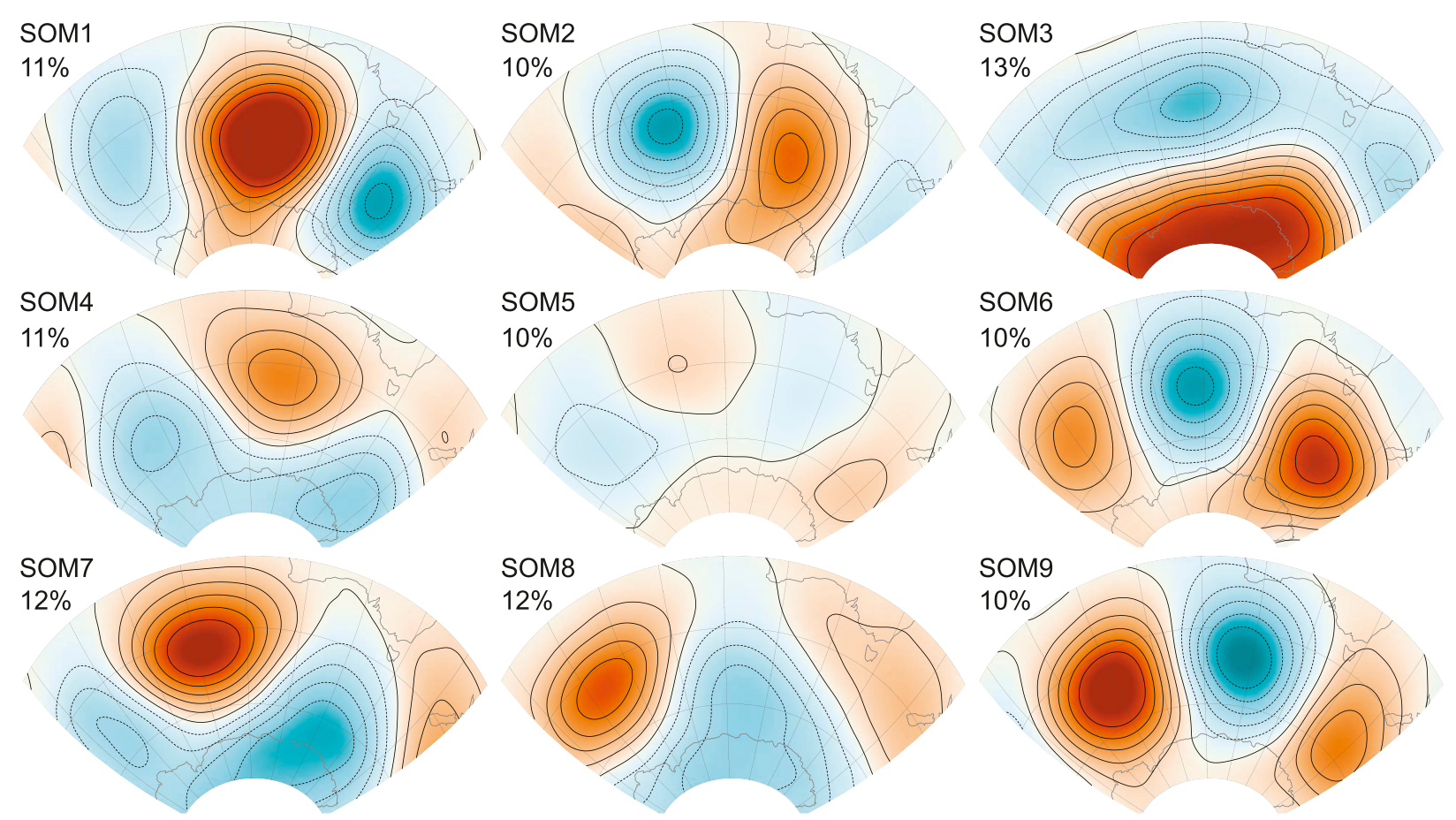

500hPa Geopotential Height Anomaly (m)

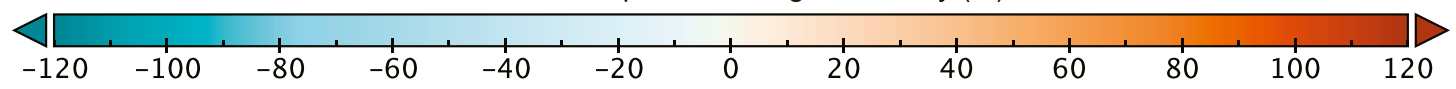

FIG. 3. Self-organizing map (SOM) output of 500-hPa geopotential height anomaly for each of the nine SOM nodes. Positive (negative) height anomalies are shown in red (blue) with solid (dotted) contours. The total frequency of each SOM node over the full analysis period (January 1979-October 2018) is shown below the SOM node label (i.e., SOM1 occurs 11\% of the time). The center of the positive geopotential height anomalies represents regions of anticyclonic ridging into the middle and high latitudes, rather than reflecting the center of the actual surface anticyclone. Refer to Fig. 4 for the climatological mean over the analysis period.

\section{(ii) SOM2-Negative anomaly at $55^{\circ} \mathrm{S}, 90^{\circ} \mathrm{E}$}

SOM2 represents the eastward progression of SOM1, with the positive height anomaly shifting eastward and the negative height anomaly to the west strengthening. The key characteristics are a strong negative and positive height anomaly from west to east across the domain, with a strong pressure gradient between $100^{\circ}$ and $120^{\circ} \mathrm{E}$. The positive height anomaly in the Southern Ocean across the Great Australian Bight region extends to the Antarctic coastline near Dumont d'Urville station in Adélie land. The negative height anomaly, west of the high, extends from $\sim 35^{\circ} \mathrm{S}$ to the East Antarctic coastline near Davis station. SOM 2 is persistent for $5 \%$ of the analysis period, and predominantly transitions to SOM6.

\section{(iii) SOM6-Positive anomaly at $\sim 55^{\circ} \mathrm{S}, 150^{\circ} \mathrm{E}$}

SOM6 represents the eastward progression of SOM2 and is characterized by a strong positive height anomaly in the southern Tasman Sea region between $135^{\circ}$ and $165^{\circ} \mathrm{E}$ and a strong negative anomaly to the west. The positive height anomaly extends from southeast Australia $\left(\sim 40^{\circ} \mathrm{S}\right)$ to the Antarctic coastline $\left(\sim 66^{\circ} \mathrm{S}\right)$ near Dumont d'Urville station, with a ridge extending farther inland. SOM 6 is persistent $6 \%$ of the analysis period and predominantly transitions to SOM9.

\section{(iv) SOM9-Positive anomaly at $\sim 55^{\circ} \mathrm{S}, 165^{\circ} \mathrm{E}$}

SOM9 represents a slight eastward shift from SOM6, with the Tasman Sea positive height anomaly shifted toward New Zealand $\left(\sim 165^{\circ} \mathrm{E}\right)$ and the negative height shifted

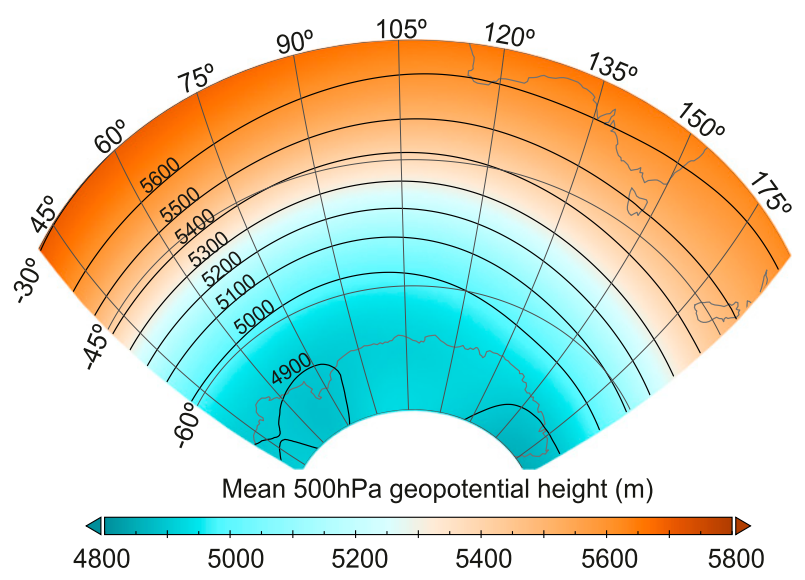

FIG. 4. 500-hPa geopotential height climatological mean in the study region over the analysis period (January 1979-October 2018). 

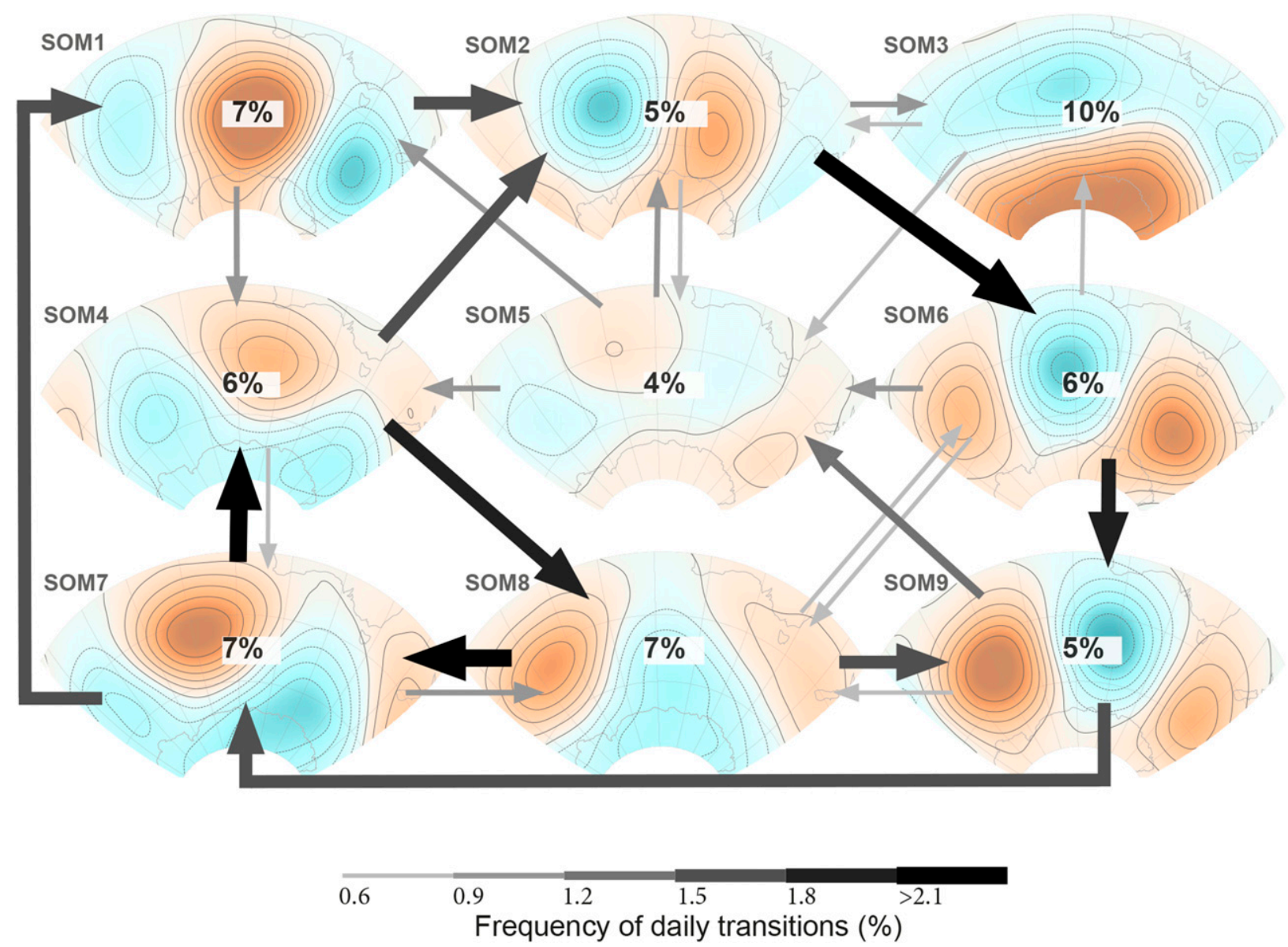

FIG. 5. Frequency of daily persistent patterns (day $t+1=$ day $t)$ and daily transition directions ( $>0.6 \%$ of days) between SOM nodes over the analysis period (January 1979-October 2018). The percentage value in the middle of the SOM composite map represents daily persistence of each node (e.g., SOM1 $=7 \%$ ), with two consecutive days classified into the same node. Across all nine SOM nodes, daily persistence accounts for $57 \%$ of the analysis period. The daily transition frequencies over the analysis period, ranging from $0.6 \%$ ( 87 days) to $2.3 \%$ (334 days), are represented by arrows between the nodes, with higher daily frequency transitions represented by thick black arrows and lower daily frequency transitions represented by thin gray arrows. Transitions between individual nodes less than $0.6 \%$ are not shown in the figure due to complexity, but include 41 different combinations (e.g., SOM 3 to SOM6) and account for a total of $11 \%$ of the analysis period. Between the corner nodes, no transitions occur between the left bottom corner (SOM7, SOM8, or SOM4) to SOM3 and vice versa, except for SOM3 to SOM4, which occurred once. Transition from SOM9 to SOM1 are more common (0.3\%) compared to transitions from SOM1 to SOM9 $(0.16 \%)$.

south of Australia $\left(\sim 120^{\circ} \mathrm{E}\right)$. SOM9 is persistent for $5 \%$ of the analysis period and predominantly transitions to SOM7.

\section{2) MIXED AND ZONAL NODES}

\section{(i) SOM7-Zonal-meridional}

SOM7 is a mix between zonal and meridional anomalies, with a broad asymmetric region of negative height anomalies over Antarctica and a positive height anomaly southwest of Australia around $45^{\circ} \mathrm{S}, 90^{\circ} \mathrm{E}$. Two troughs on either side of the positive anomaly extend equatorward along $60^{\circ}$ and $135^{\circ} \mathrm{E}$ from the negative anomaly over East Antarctica. SOM7 is persistent for $7 \%$ of the analysis period and predominantly transitions to SOM4.

\section{(ii) SOM4-Zonal-meridional}

SOM4 is also characterized by a broad asymmetric region of negative height anomalies over Antarctica that extend equatorward around the positive height anomaly, which is shifted eastward compared to SOM7 $\left(\sim 115^{\circ} \mathrm{E}\right)$. SOM4 is persistent for $6 \%$ of the analysis period and generally transitions to SOM 8 $(1.8 \%)$ and SOM2 (1.5\%).

\section{(iii) SOM8-Zonal-meridional}

SOM8 is characterized by a broad asymmetric region of negative height anomalies over Antarctica, with a trough extending equatorward around $105^{\circ} \mathrm{E}$. Two regions of positive height anomalies are located in the midlatitudes either side of 


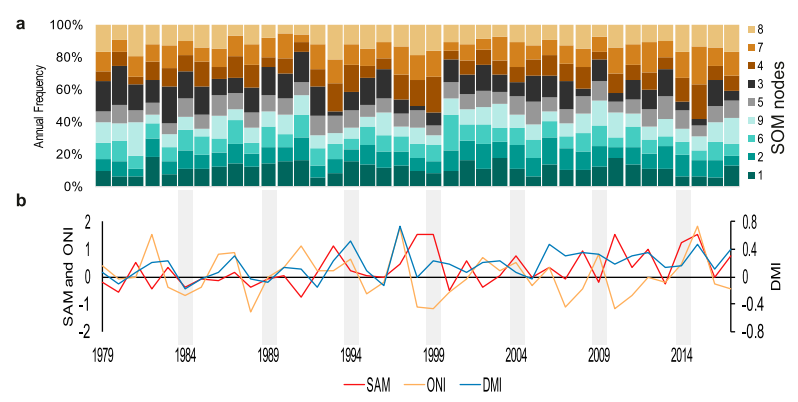

FIG. 6. (a) Annual (June-May) frequency of each SOM node. Each color refers to the proportion (\%) of the year classified as a particular SOM node (1-9) ordered from meridional at the bottom to zonal-mixed nodes at the top. For example, between June 1979 and May 1980, 19\% of the period (70 days) was classified as SOM3. (b) Annual (June-May) average index of SAM (southern annular mode using the Marshall index), ONI (oceanic Niño index representing ENSO phase), and DMI (dipole mode index representing Indian Ocean dipole phase). Year corresponds to the JuneDecember period of each 12-month period for both (a) and (b). Gray rectangles provide a year guide every 5 years.

the trough. SOM8 is persistent for $7 \%$ of the analysis period and generally transitions into SOM7 (2.1\%) and SOM9 (1.6\%).

\section{(iv) SOM3-Zonal}

SOM3 displays a zonal structure with negative height anomalies in the midlatitudes and positive height anomalies in the high latitudes over Antarctica. The height anomalies are slightly asymmetric, with the strongest negative anomaly focused around $45^{\circ} \mathrm{S}, 105^{\circ} \mathrm{E}$ and a ridge extending equatorward between $135^{\circ}$ and $150^{\circ} \mathrm{E}$ to approximately $55^{\circ} \mathrm{S}$. The seasonal frequency of SOM3, which peaks in JJA and SON (Fig. S1 in the online supplemental material) is consistent with the JJA equatorward shift of the Antarctic circumpolar trough. SOM3 has the highest frequency of daily persistence (10\%), and as such has a relatively low frequency of transitions to neighboring nodes compared to other SOM nodes. SOM3 never transitions to SOM7 and vice versa.

\section{3) TRANSITION NODE (SOM5)}

SOM5 is characterized by weak anomalies with no clear distinguishing features and often represents the transition between all other nodes. Analysis of the individual daily weather patterns assigned to SOM5 suggests that the node represents a diversity of low-frequency patterns that are not consistent with the broader patterns represented by the surrounding nodes. For example, cutoff lows over both southwest and southeast Australia are frequently included in this SOM node.

\section{b. Frequency of occurrence and interannual variability}

The nine synoptic types identified each display similar frequency, ranging between $10 \%$ and $13 \%$ (Fig. 3), over the full analysis period (January 1979-October 2018). Seasonally, SOM3 peaks in JJA (16\%) and SON (14\%) (Fig. S1). The opposing node, SOM7, also peaks in JJA (14\%). The seasonal peak for the meridional nodes is generally MAM. While the annual and seasonal frequency is similar between the SOM nodes over the analysis period, the year-to-year frequency

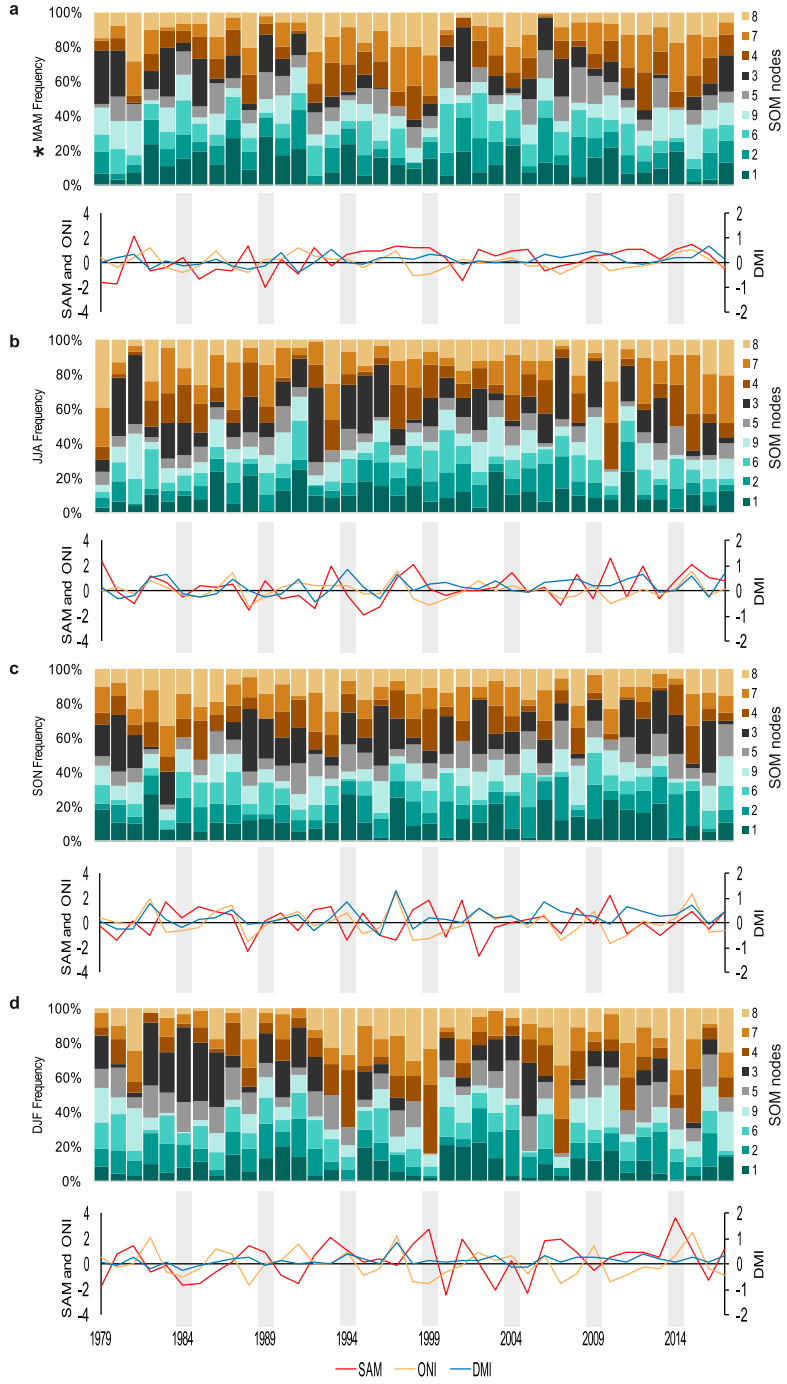

FIG. 7. Seasonal frequency for (a) austral autumn (MAM), (b) winter (JJA), (c) spring (SON), and (d) summer (DJF) of each SOM node and the corresponding seasonal average index of SAM (southern annular mode using the Marshall index), ONI (oceanic Niño index representing ENSO phase) and DMI (dipole mode index representing Indian Ocean dipole phase). SOM nodes (1-9) are represented by a unique color and ordered from meridional at the bottom to zonal-mixed nodes at the top. Year corresponds to the December year. For the MAM frequency plot, note that the actual year of occurrence is equal to year +1 (e.g., MAM 2009 in figure represents the period March-May 2010). Gray rectangles provide a year guide every 5 years. Frequency plots represent the proportion of the season classified to a particular SOM node [e.g., in 1979 DJF $19.8 \%$ of the period (18 days) was classified as SOM3].

distribution is highly variable (Figs. 6 and 7). On an annual time scale, the frequency of each SOM node ranged from $3 \%$ to $24 \%$. SOM3 displayed the highest interannual variability, on both an annual and seasonal time scale, and generally follows a similar interannual pattern to the meridional nodes. Increased frequency of the mixed nodes (SOM4, SOM7, and SOM8) correspond with reduced frequency of SOM3 and the meridional nodes. 
TABLE 1. Annual (June-May year) Spearman correlations and statistical significance (two-sided Student's $t$ test) over the period June 1979-May 2018 between annual occurrence of SOM nodes and annual average index representing climate variability modes; southern annular mode (SAM; using the Marshall index), Indian Ocean dipole (IOD; using the dipole mode index), three ENSO indices-Niño-4, ONI (oceanic Niño index), and SOI (Southern Oscillation index)—and blocking index over three sectors in the Australian region (Southeast Indian Ocean: BI SEIO between $90^{\circ}$ and $120^{\circ}$ E; Southern Australia: BI SA between $120^{\circ}$ and $150^{\circ} \mathrm{E}$; Tasman Sea: BI TS between $150^{\circ}$ and $180^{\circ} \mathrm{E}$ ). All time series were detrended prior to correlation and no autocorrelation was detected at lag-1. Correlation significance $\geq 99 \%$ are in boldface, at $95 \%$ are shown in normal type, and $<95 \%$ are blank.

\begin{tabular}{|c|c|c|c|c|c|c|c|c|}
\hline SOM node & SAM & IOD & Niño-4 & ONI & SOI & BI SEIO & BI SA & BI TS \\
\hline \multicolumn{9}{|l|}{1} \\
\hline 2 & -0.59 & & & & & & & \\
\hline 3 & -0.69 & -0.36 & & & & & & \\
\hline 4 & 0.57 & 0.34 & & & & & & \\
\hline 5 & & -0.39 & & & & -0.36 & & \\
\hline 6 & -0.34 & & & & & & & \\
\hline 7 & 0.77 & & & & & 0.34 & & \\
\hline 8 & 0.58 & & -0.35 & & & & & \\
\hline 9 & & & & & & & & \\
\hline
\end{tabular}

SAM is significantly correlated with six of the nine synoptic types at interannual time scales (Table 1). Seasonally, SOM3 is strongly correlated with SAM - conditions, while SOM7 and SOM8 are moderately to strongly correlated with SAM+ conditions (Table 2). The dominant SAM+ node (i.e., strongest seasonal correlation) switches seasonally between SOM7 (JJA) and SOM8 (SON, DJF, MAM). In select seasons, significant correlations were also found between SAM- and SOM1/SOM2, and SAM+ and SOM4/SOM6 (Table 2).

The association between ENSO and the occurrence of synoptic types is variable, depending on the index, time period, and seasons selected. Significant correlations between SOM nodes and both atmospheric (SOI) and oceanic (ONI or Niño-4) ENSO indices were only found in SON/DJF over the analysis period for SOM2 in SON (El Niño) and SOM7 in DJF (La Niña). With the exception of SOM7 $\sim$ SOI in DJF $(\rho=0.42, p<0.01, n=39)$, the remaining statistically significant correlations between synoptictype frequency and ENSO index were significant at the $95 \%$ confidence level (Table 2). Additionally, some of these relationships were only statistically significant with the SOI, potentially indicating that the Indian Ocean may be influencing the western pole of the index (Behera and Yamagata 2003).

The IOD was significantly correlated with SOM3, SOM4, and SOM5 at interannual time scales. However, as the IOD is seasonally phase locked by the wind reversal associated with the Northern Hemisphere monsoon over India and Asia (Cai et al. 2013), we focused on the seasonal results between JJA and DJF. An IOD event generally develops during MAM and peaks between August-October before decaying with the arrival of the Australian monsoon around November (Saji et al. 1999). Seasonally, only SOM1 and SOM9 were significantly correlated in the IOD peak season (Table 2). The strength of these relationships was sensitive to the test used with higher $r$ values for the Pearson versus Spearman method (Table S2; Table 2).

Blocking in the three regions investigated (southeast Indian Ocean, southern Australia, and Tasman Sea) was significantly correlated with at least one node in each season (Table 2). The strongest correlations were observed in SON, with SOM6 and SOM8 associated with blocking in southern Australia and the Tasman Sea, and SOM7 associated with blocking in the southeast Indian Ocean (Table 2). SOM3 is associated with a lack of blocking across all three regions during SON.

\section{Discussion}

Our results first show that the regional synoptic representation of SAM + conditions in the southern Indian Ocean is not zonally symmetric. This is consistent with literature emphasizing that the physical interpretation of an assumed annular structure of SAM is complicated due to regional and seasonal differences in the dynamics, shape, and impact of SAM across the Southern Ocean region (e.g., Codron 2007; Kidston et al. 2009; Barnes and Hartmann 2010; Ding et al. 2012; Spensberger et al. 2019). Our Indian Ocean sector results for SAM+ conditions are consistent with those of Ding et al. (2012), who described the SAM signature in the Indian Ocean as a zonally elongated meridional dipole. The positive height anomaly in SOM7 and SOM8 aligns with the region of meridional shift of the eddy-driven jet over the Indian Ocean (Ding et al. 2012) and associated anticyclonic wave breaking during JJA SAM+ conditions (Spensberger et al. 2019). During JJA, all three mixed SOM nodes are significantly correlated with SAM $+(\rho \geq 0.47, p<0.01, n=39$; Table 2$)$. None of these nodes were individually characterized as being zonally symmetric. Interestingly, the asymmetry in the negative height anomaly of the strongly correlated SAM + synoptic types across all seasons (SOM7/SOM8) falls between the midlatitude stations (Ile Amsterdam at $37.83^{\circ} \mathrm{S}, 77.5^{\circ} \mathrm{E}$ and Hobart at $42.88^{\circ} \mathrm{S}, 147.3^{\circ} \mathrm{E}$ ) used to derive the Marshall SAM index in this region. The combined region of negative height anomaly asymmetry in SOM7 and SOM8 is also consistent with the hemispheric clusters representing SAM + undertaken by Pohl and Fauchereau (2012).

In contrast to the mixed nodes, the zonal anomaly pattern of SOM3 is more consistent with the hemispheric symmetric SAM structure interpretation. The regional representation of the negative phase of SAM associated with SOM3 is consistent with the hemispheric cluster representing SAM - in Pohl and Fauchereau (2012). However, SOM2, which represents meridional conditions, is also strongly correlated $(\rho=-0.43$, 
TABLE 2. Seasonal Spearman correlations and statistical significance (two-sided Student's $t$ test) over the period June 1979-May 2018 between seasonal occurrence of SOM nodes and seasonal average index representing climate variability modes; southern annular mode (SAM; using Marshall index), Indian Ocean dipole (IOD; using the dipole mode index), three ENSO indices [Niño-4, ONI (oceanic Niño index), and SOI (Southern Oscillation index)], and blocking index over three sectors in the Australian region (southeast Indian Ocean: BI SEIO between $90^{\circ}$ and $120^{\circ} \mathrm{E}$; southern Australia: BI SA between $120^{\circ}$ and $150^{\circ} \mathrm{E}$; Tasman Sea: BI TS between $150^{\circ}$ and $180^{\circ} \mathrm{E}$ ). All time series were detrended prior to correlation and no autocorrelation was detected at lag-1. Correlation significance $\geq 99 \%$ are in boldface, at $95 \%$ are shown in normal type, and $<95 \%$ are blank.

\begin{tabular}{|c|c|c|c|c|c|c|c|c|}
\hline SOM node & SAM & IOD & Niño-4 & ONI & SOI & BI SEIO & BI SA & BI TS \\
\hline \multicolumn{9}{|l|}{ JJA } \\
\hline 1 & -0.33 & & & & & 0.47 & & \\
\hline 2 & -0.33 & & & & & & & \\
\hline 3 & -0.78 & & & & & & & \\
\hline 4 & 0.47 & & & & & & & \\
\hline \multicolumn{9}{|l|}{5} \\
\hline \multicolumn{9}{|l|}{6} \\
\hline 7 & 0.74 & & & & & & & \\
\hline 8 & 0.53 & & & & & & & \\
\hline 9 & & & & & & & 0.40 & \\
\hline \multicolumn{9}{|l|}{ SON } \\
\hline 1 & & 0.34 & & & & & & \\
\hline 2 & & & 0.32 & & -0.32 & & & \\
\hline 3 & -0.72 & & & & & -0.48 & -0.6 & -0.51 \\
\hline \multirow{2}{*}{\multicolumn{9}{|c|}{-0.41}} \\
\hline & & & & & & & & \\
\hline 6 & 0.37 & & & & & & 0.61 & 0.56 \\
\hline 7 & 0.50 & & & & & 0.51 & & \\
\hline 8 & 0.66 & & & & & & 0.38 & 0.49 \\
\hline 9 & & -0.36 & & & 0.37 & & & \\
\hline \multicolumn{9}{|l|}{ DJF } \\
\hline 1 & -0.33 & & & & & & & \\
\hline 2 & -0.33 & & & & -0.33 & & & -0.34 \\
\hline 3 & -0.78 & & & & -0.34 & & & -0.32 \\
\hline 4 & 0.57 & & & & & & & \\
\hline 5 & & & & & -0.32 & -0.58 & -0.34 & \\
\hline \multicolumn{9}{|l|}{6} \\
\hline 7 & 0.40 & 0.41 & & -0.33 & 0.42 & 0.50 & & 0.33 \\
\hline 8 & 0.67 & & & & & & & 0.46 \\
\hline 9 & & & & & & & -0.33 & \\
\hline \multicolumn{9}{|l|}{ MAM } \\
\hline 1 & & & & & & 0.53 & & -0.41 \\
\hline 2 & -0.43 & & & & & & 0.44 & \\
\hline 3 & -0.75 & & & & & -0.47 & & \\
\hline \multicolumn{9}{|l|}{4} \\
\hline 5 & & 0.36 & & & & & & \\
\hline 6 & & & & & & & & 0.37 \\
\hline 7 & 0.68 & & & 0.33 & & 0.34 & & \\
\hline 8 & 0.69 & & & & & & -0.37 & \\
\hline 9 & & & & & & & & \\
\hline
\end{tabular}

$p<0.01, n=39$ ) with SAM - in MAM, suggesting that regional asymmetries are also important to consider during SAM - conditions.

\section{a. Seasonal SOM frequency and connections to southeast Australian climate}

The surface weather conditions across southeast Australia associated with synoptic types that are strongly seasonally correlated with SAM (SOM3, SOM4, SOM7, and SOM8) are likely to be consistent with the seasonal influence of SAM on regional climate (e.g., Gillett et al. 2006; Hendon et al. 2007). The precipitation associated with meridional nodes (SOM1, SOM2, SOM6, and SOM9) across southern Australia is likely to be variable depending on the location of the positive height anomaly and associated surface-level high pressure system (e.g., Risbey et al. 2009). For example, atmospheric blocking in the Great Australian Bight region (e.g., SOM2) is associated with increased rainfall in western Australia, while blocking 
farther east in the Tasman Sea region (e.g., SOM6) favors increased rainfall across southeast Australia (Risbey et al. 2009). The positive height anomalies of SOM4 and SOM8 (mixed nodes) are also consistent with these Australian blocking regions and may similarly influence Australian precipitation. The following section discusses the compound seasonal influence of modes of climate variability investigated on the observed synoptic-type frequency and provides potential physical insights into precipitation responses over southeast Australia.

\section{1) Autumn AND Winter (MAM AND JJA)}

During MAM/JJA, the interannual variability in SOM frequency is associated with variations in SAM phase and strength (Figs. 7a,b; Table 2). Consecutive SAM + autumns between 1993-2000, 2003-06, and 2010-17 corresponded with increased frequency of SOM4, SOM7, and SOM8 and decreased frequency or no occurrence of SOM3. These periods align with below average MAM precipitation over southeast Australia (Cai and Cowan 2008, 2013; Murphy and Timbal 2008; VerdonKidd and Kiem 2009; Kiem and Verdon-Kidd 2010). Below average MAM precipitation, leading to dry catchments and less runoff, has been identified as a key driver of the disproportionate annual streamflow reduction compared to the annual rainfall reduction observed across Victoria during the Millennium Drought (Kiem and Verdon-Kidd 2010; Cai and Cowan 2013). This is consistent with reduced precipitation associated with SAM+ events in southeast Australia during late MAM/JJA (Hendon et al. 2007; Ho et al. 2012). Over subtropical eastern Australia (southern Queensland/New South Wales), the relationship between SAM phase and precipitation is reversed compared to that in southeast Australia (Victoria/Tasmania). Due to anomalous easterly winds enhancing moisture advection from the ocean, SAM+ is associated with increased MAM/JJA precipitation along the east coast of Australia (Gillett et al. 2006; Sen Gupta and England 2006; Hendon et al. 2007). This suggests that years with increased frequency of SOM4, SOM7, and/or SOM8 during MAM/JJA may be associated with above average seasonal rainfall over the east coast of Australia and reduced seasonal rainfall across southeast Australia (e.g., MAM 2013).

\section{2) SPRING (SON)}

The response of synoptic-type frequency to the modes of climate variability in SON is dependent on the node (Fig. 7c, Table 2). Increased frequency of the mixed nodes (SOM4, SOM7, and SOM8) and SOM6 are associated with SAM+ conditions. Additionally, SOM6 and SOM8 are associated with blocking conditions in the Tasman Sea, consistent with more favorable blocking conditions during SAM+ (Jiang et al. 2013). The combined influence of Tasman Sea blocking and $\mathrm{SAM}+$ conditions during SON are important drivers of increased precipitation across eastern Australia (Risbey et al. 2009). While both SOM6 and SOM8 are associated with Tasman Sea blocking, the anomaly patterns represent different "flavors" of blocking in this region. As such they are likely to be associated with different surface conditions in eastern Australia and East Antarctica. The Tasman Sea blocking setup represented by SOM8 is likely to be associated with increased precipitation over eastern Australia (Risbey et al. 2009), while SOM6 is more likely to influence precipitation in East Antarctica near Law Dome (McMorrow et al. 2004; Scarchilli et al. 2011).

Variability in the frequency of the remaining meridional nodes (SOM1, SOM9, and SOM2) were associated with tropical modes of climate variability rather than SAM. Increased SOM1 frequency was statistically significantly related ( $\rho=$ $0.34, p<0.05, n=39$ ) with IOD+ events, for example, extreme positive IOD events in 1994 and 1997 (Fig. 7c). The positive anomaly in SOM1 along $115^{\circ} \mathrm{E}$ is consistent with the positive anomaly associated with the "observed" Indian Ocean atmospheric Rossby wave train (McIntosh and Hendon 2018). The offshore wind anomalies along the coastline of western Australia associated with the height anomalies in SOM1 support the tropical easterly wind anomalies observed in IOD+ (Saji et al. 1999). Increased SOM9 frequency was weakly associated with negative IOD (DMI: $\rho=-0.36, p<0.05, n=39$ ) and La Niña (based on SOI: $\rho=0.37, p<0.05, n=39$ ), which can co-occur during SON leading to increased precipitation and flood risk in eastern Australia (Behera and Yamagata 2003; Risbey et al. 2009; Hendon et al. 2014). The negative anomaly of SOM9 over southwest Australia aligns with circulation anomalies associated with La Niña and negative IOD events (Cai et al. 2011; McIntosh and Hendon 2018).

Increased frequency of SOM3 during SON is strongly associated with SAM - $(\rho=-0.78, p<0.001, n=39)$. Eastern Australia generally experiences a reduction in precipitation during SON and DJF periods characterized by SAM- conditions (Risbey et al. 2009), suggesting that SOM3 is likely to be associated with dry conditions across eastern Australia. Additionally, between late September to early January, the strength of the stratospheric vortex also influences tropospheric weather patterns over the Southern Ocean (Lim et al. 2018). The seesaw interannual variability (Fig. 7c) and annual inverse correlation (not shown) between SOM3 and the mixed nodes representing SAM + is consistent with the stratospheretroposphere coupled mode developed by Lim et al. (2018) to categorize strong and weak polar vortex years. Weak polar vortex years (e.g., 1988, 2002), where the vortex breaks down in early SON (Lim et al. 2018), are associated with an increased frequency of SOM3. These years correspond with reduced frequency of the mixed nodes (SOM4, SOM7, and SOM8) and vice versa for strong vortex years (e.g., 1998, 1999). This is consistent with the findings of Lim et al. (2018), who found that anomalous SH weakening (early breakdown) or strengthening (late breakdown) of the polar vortex during SON often leads to sustained occurrence of the negative or positive phase of SAM, respectively.

\section{3) SuMMER (DJF)}

The overall response to SAM phase and strength during DJF appears enhanced (suppressed) due to ENSO and/or IOD being in phase (out of phase) with circulation anomalies in the region (Fig. 7d). This is consistent with findings from previous studies that a significant proportion of austral warm season SAM variation is influenced by ENSO (Karoly 1990; L'Heureux and Thompson 2006; Lim et al. 2013). DJF periods 
when all modes are in phase supporting SAM + (i.e., La Niña; IOD-/neutral) circulation anomalies (e.g., 1999/2000, 2007/ $08)$ show the highest seasonal frequency $(>80 \%)$ of SOM 4 , SOM7, and SOM8 along with the lowest frequencies of SOM3 and meridional nodes (Fig. 7d). SOM4 and SOM8 are strongly correlated with SAM+ during DJF; however, SOM7 variability is potentially influenced by a combination of SAM + and La Niña (Table 2; Fig. 7d). It is also associated with more favorable conditions for Tasman Sea blocking (Table 2). This combination of modes of climate variability (SAM+/La Niña) and blocking align with the leading drivers of eastern Australian precipitation in DJF, with La Niña/SAM+ dominant across subtropical eastern Australia and blocking/SAM+ across southeast Australia (Risbey et al. 2009).

The in-phase SAM + DJF periods are not always characterized by increased frequency of SOM4, SOM7, and SOM8. For example, an increase of meridional nodes (in particular SOM9) occurred in 2010/11 when eastern Australia experienced widespread flooding linked to very strong La Niña, negative IOD, SAM+, and Tasman Sea blocking conditions (Hendon et al. 2014; Cleverly et al. 2016). While SOM9 is not significantly correlated to any of these modes of variability or blocking indices in DJF, the frequency during DJF 2010/11 was equal highest (24.4\%) in the analysis period (with DJF 1981/82; Fig. 7d). This suggests that the circulation anomalies over eastern Australia associated with the eastward-shifted Tasman Sea blocking in SOM9 may be an important driver for increased precipitation and flood risk in eastern Australia during unusual years such as 2010/11. Further exploration of this link is beyond the scope of the current study, but is of interest for future work.

DJF seasons characterized by in-phase SAM - conditions (e.g., 1979/80, 1991/92, and 2003/04) align with increased frequency of SOM3 and select meridional nodes (SOM1, SOM2). However, this does not explain all years with increased meridional frequency - for example, DJF 1989/90, which was associated with neutral conditions for all three climate modes investigated. Additionally, 1989 is well known for increased Tasman Sea blocking (Pook 1994), which is reflected in the increased occurrence of SOM6 in SON and DJF (Figs. 7c,d). Over eastern Australia, Tasman Sea blocking highs are associated with moist easterly flow into coastal regions, which provide favorable conditions for increased chance of coastal precipitation (Pepler et al. 2019b). The occurrence of strong anticyclonic ridges over the mid- to high latitudes of the Tasman Sea is also associated with decreased anticyclone activity farther north and vice versa (Pepler et al. 2019b).

\section{b. East Antarctica and ice core implications}

Over East Antarctica, SAM+ is generally associated with increased westerly wind strength near $60^{\circ} \mathrm{S}$, equatorward moisture flux, and decreased snowfall (Marshall et al. 2017), consistent with the anomaly patterns of SOM4, SOM7, and SOM8. The combined geopotential height anomaly pattern of SOM4 and SOM7 is also similar to low snowfall years at Law Dome (van Ommen and Morgan 2010; Roberts et al. 2015). The synoptic setup of SOM4 and SOM7 in the Law Dome region is likely associated with increased westerly wind strength and/or reversal of polar easterlies. Due to the eastward facing orientation of Law Dome, a reduction in the strength of polar easterlies and/or increased westerly wind strength is likely to be associated with decreased orographic precipitation (McMorrow et al. 2004).

In contrast, the strong pressure gradient between positive height anomalies over Antarctica and negative anomalies over the Southern Ocean observed in SOM3 provides a likely mechanism for enhanced polar easterly winds along the Antarctic coastline and orographic precipitation on east facing slopes (e.g., Law Dome). This is consistent with increased precipitation during SAM - conditions across East Antarctica (Marshall et al. 2017). The cyclones associated with SOM3 are consistent with the mean cyclone conditions of the region (Simmonds et al. 2003). Precipitation associated with these cyclones along the Antarctic coast is often orographically induced and rarely penetrates inland over the Antarctic Plateau (Bromwich 1988; Cullather et al. 1998).

The meridional nodes are more likely to be associated with the transport of warm, moist air from the midlatitudes to the Antarctic coastline and plateau regions (Irving and Simmonds 2015) along the western boundary of the positive height anomaly (e.g., within the $75^{\circ}-90^{\circ} \mathrm{E}$ meridian range in SOM1). This synoptic situation often represents a blocking high pressure system extending a ridge to the Antarctic coastline and an "upstream" extratropical cyclone that moves poleward and intensifies rapidly in the strong baroclinic zone between the cold low pressure system to the west and warm high pressure ridge to the east (Scarchilli et al. 2011; Sinclair and Dacre 2019). When these features interact with the Antarctic coastline, they are often associated with increased precipitation and temperature (Massom et al. 2004; Scarchilli et al. 2011; Gorodetskaya et al. 2014; Schlosser et al. 2017; Wille et al. 2019). For example, back trajectory analysis (1980-2001) attributed Tasman Sea atmospheric blocking with up to $40 \%$ of the snowfall events at Law Dome (Scarchilli et al. 2011). The high pressure ridge also provides a mechanism for extratropical cyclones to penetrate inland over the East Antarctic Ice Sheet, with Tasman Sea blocks attributed to $20 \%$ of the snowfall events at Dome C (Scarchilli et al. 2011). The anomaly patterns of SOM6 and SOM9 are consistent with a Tasman Sea high pressure ridge extending to Antarctica. The key difference between these nodes is the longitudinal shift in the center of the positive height anomaly, which would be expected to shift the region of precipitation influence in Antarctica.

The synoptic features of the meridional nodes are more likely to result in episodic precipitation at ice core sites which is important to consider for interpretation of paleoclimate proxies (Turner et al. 2019). Additionally, our findings show that the frequency of the meridional nodes is not significantly related to the phase of SAM. This finding, along with regional asymmetric representation of $\mathrm{SAM}+$ conditions, could potentially explain the lack of a significant SAM signal in Law Dome snowfall accumulation rate (van Ommen and Morgan 2010) and sea salt record (Vance et al. 2013) in contrast to ice core records from West Antarctica and South America (Abram et al. 2014; Hessl et al. 2017). The relationship between synoptic types, modes of climate variability, and favorable synoptic situations for increased or decreased 
precipitation over East Antarctica is important to consider for interpretation of climate proxy records from ice cores. Future work investigating the surface conditions associated with the synoptic types and how they are preserved in ice core records may assist with diagnosing the missing link between ice core records, modes of climate variability, and teleconnections to midlatitude climate.

\section{Conclusions}

This study has identified the diversity of synoptic-scale variability of the SIO, and a lack of dominance of zonal patterns. This diversity has implications for understanding Antarctic and southern Australia climate variability, and will allow improved interpretation of climate proxy records derived from East Antarctic ice cores and other regional archives.

The nine synoptic types represented by the nodes defined in this study included four meridional (SOM1, SOM2, SOM6, and SOM9), three mixed (SOM4, SOM7, and SOM8), a zonal (SOM3), and a transitional pattern (SOM5). The meridional nodes represent anomaly patterns that are favorable for transporting warm, moist air masses to the Antarctic region and are likely associated with increased precipitation and temperature along the Antarctic coastline. The frequency of the meridional nodes shows limited association with SAM phase, especially during SON. In contrast, the zonal and mixed nodes were strongly correlated with SAM (negative and positive, respectively) in most seasons, however, the regional synoptic representation of SAM+ is not zonally symmetric, and is represented by three separate nodes. Consideration of these different "flavors" of SAM+ conditions may help explain the varied precipitation response over southern and eastern Australia, as well as East Antarctic ice core records to SAM variability. The interannual variability of synoptic-type frequency over MAM/ JJA in the SIO is generally associated with the phase and strength of SAM, rather than ENSO or IOD. In SON/DJF the SAM association remains; however, the synoptic-type frequency response to SAM tends to be enhanced (suppressed) if ENSO and/or IOD phase favor (oppose) the circulation anomalies of the region.

Future work investigating the surface conditions associated with the synoptic types and how/if they are preserved in coastal East Antarctic ice core records may broaden the application of these ice cores to provide a longer time perspective of synoptic weather conditions in the southern Indian Ocean.

Acknowledgments. DU is supported by an Australian Research Training Program scholarship and the Australian Research Council (ARC) Centre of Excellence for Climate Extremes. TV and AK acknowledge support from an ARC Discovery Project (DP180102522). TV also acknowledges support from the ARC Special Research Initiative for Antarctic Gateway Partnership (SR140300001) and the Australian Antarctic Program Partnership (ASCI000002). NH acknowledges support from the ARC Centre of Excellence for Climate Extremes (CE170100023). Analyses were undertaken with assistance from the National Computational Infrastructure (NCI), supported by the Australian Government. We thank James Risbey, Mike Pook, and Carly Tozer for helpful discussions and engagement around this work. The authors declare no known conflict of interest. This work contributes to Australian Antarctic Science projects (4414, 4537, and 4061) and a National Science Foundation project (NSF P2C2 18041212).

Data availability statement. The derived SOM output for the period January 1979-October 2018 is available at the Australian Antarctic Data Centre: https://doi.org/10.4225/15/58eedf00d78fe. The ERA-Interim data used for input into the SOM algorithm are publicly available from https://apps.ecmwf.int/datasets/. The SOM analysis was performed in R using the "Kohonen" package and is publicly available through https://cran.r-project.org/web/ packages/kohonen/index.html. The Marshall station index, representing the southern annular mode (Marshall 2003) is available from https://legacy.bas.ac.uk/met/gjma/sam.html. The monthly Dipole Mode Index, representing the Indian Ocean dipole (Saji et al. 1999), is available from http://www.jamstec.go.jp/ aplinfo/sintexf/iod/dipole_mode_index.html. The indices used to represent El Niño-Southern Oscillation are available from the Australian Bureau of Meteorology (SOI: http://www.bom.gov.au/ climate/current/soi2.shtml) and the National Centre for Atmospheric Research (Niño4 and ONI: https://climatedataguide.ucar.edu/ climate-data/nino-sst-indices-nino-12-3-34-4-oni-and-tni).

\section{REFERENCES}

Abram, N. J., R. Mulvaney, F. Vimeux, S. J. Phipps, J. Turner, and M. H. England, 2014: Evolution of the southern annular mode during the past millennium. Nat. Climate Change, 4, 564-569, https://doi.org/10.1038/nclimate2235.

— B. C. Dixon, M. G. Rosevear, B. Plunkett, M. K. Gagan, W. S. Hantoro, and S. J. Phipps, 2015: Optimized coral reconstructions of the Indian Ocean dipole: An assessment of location and length considerations. Paleoceanography, 30, 1391-1405, https://doi.org/10.1002/2015PA002810.

—, J. A. Hargreaves, N. M. Wright, K. Thirumalai, C. C. Ummenhofer, and M. H. England, 2020: Palaeoclimate perspectives on the Indian Ocean dipole. Quat. Sci. Rev., 237, 106302, https://doi.org/10.1016/j.quascirev.2020.106302.

Armstrong, M. S., A. S. Kiem, and T. R. Vance, 2020: Comparing instrumental, palaeoclimate, and projected rainfall data: Implications for water resources management and hydrological modelling. J. Hydrol. Reg. Stud., 31, 100728, https:// doi.org/10.1016/j.ejrh.2020.100728.

Barnes, E. A., and D. L. Hartmann, 2010: Dynamical feedbacks of the southern annular mode in winter and summer. J. Atmos. Sci., 67, 2320-2330, https://doi.org/10.1175/ 2010JAS3385.1.

Barry, R. G., and A. H. Perry, 2001: Synoptic climatology and its applications. Synoptic and Dynamic Climatology, R. G. Barry and A. H. Perry, Eds., Routledge, 547-603.

Behera, S. K., and T. Yamagata, 2003: Influence of the Indian Ocean dipole on the Southern Oscillation. J. Meteor. Soc. Japan, 81, 169-177, https://doi.org/10.2151/jmsj.81.169.

Bracegirdle, T. J., and G. J. Marshall, 2012: The reliability of Antarctic tropospheric pressure and temperature in the latest global reanalyses. J. Climate, 25, 7138-7146, https://doi.org/ 10.1175/JCLI-D-11-00685.1.

Bromwich, D. H., 1988: Snowfall in high southern latitudes. Rev. Geophys., 26, 149-168, https://doi.org/10.1029/RG026i001p00149.

Cai, W., and T. Cowan, 2008: Dynamics of late autumn rainfall reduction over southeastern Australia. Geophys. Res. Lett., 35, L09708, https://doi.org/10.1029/2008GL033727. 
— and _ 2013: Southeast Australia autumn rainfall reduction: A climate-change-induced poleward shift of ocean-atmosphere circulation. J. Climate, 26, 189-205, https://doi.org/10.1175/ JCLI-D-12-00035.1.

- P. van Rensch, T. Cowan, and H. H. Hendon, 2011: Teleconnection pathways of ENSO and the IOD and the mechanisms for impacts on Australian rainfall. J. Climate, 24, 3910-3923, https://doi.org/10.1175/2011JCLI4129.1.

_- X.-T. Zheng, E. Weller, M. Collins, T. Cowan, M. Lengaigne, W. Yu, and T. Yamagata, 2013: Projected response of the Indian Ocean dipole to greenhouse warming. Nat. Geosci., 6 , 999-1007, https://doi.org/10.1038/ngeo2009.

Cassano, J. J., P. Uotila, and A. Lynch, 2006: Changes in synoptic weather patterns in the polar regions in the twentieth and twenty-first centuries, part 1: Arctic. Int. J. Climatol., 26, 10271049, https://doi.org/10.1002/joc.1306.

Catto, J. L., E. Madonna, H. Joos, I. Rudeva, and I. Simmonds, 2015: Global relationship between fronts and warm conveyor belts and the impact on extreme precipitation. J. Climate, $\mathbf{2 8}$, 8411-8429, https://doi.org/10.1175/JCLI-D-15-0171.1.

Cleverly, J., and Coauthors, 2016: The importance of interacting climate modes on Australia's contribution to global carbon cycle extremes. Sci. Rep., 6, 23113, https://doi.org/10.1038/ srep23113.

Codron, F., 2007: Relations between annular modes and the mean state: Southern Hemisphere winter. J. Atmos. Sci., 64, 33283339, https://doi.org/10.1175/JAS4012.1.

Cohen, L., S. Dean, and J. Renwick, 2013: Synoptic weather types for the Ross Sea region, Antarctica. J. Climate, 26, 636-649, https://doi.org/10.1175/JCLI-D-11-00690.1.

Coughlan, M., 1983: A comparative climatology of blocking action in the two hemispheres. Aust. Meteor. Mag., 31, 3-13.

Cullather, R. I., D. H. Bromwich, and M. L. Van Woert, 1998: Spatial and temporal variability of Antarctic precipitation from atmospheric methods. J. Climate, 11, 334-367, https://doi.org/10.1175/ 1520-0442(1998)011<0334:SATVOA > 2.0.CO;2.

Dätwyler, C., M. Grosjean, N. J. Steiger, and R. Neukom, 2020: Teleconnections and relationship between the El NiñoSouthern Oscillation (ENSO) and the Southern Annular Mode (SAM) in reconstructions and models over the past millennium. Climate Past, 16, 743-756, https://doi.org/10.5194/ cp-16-743-2020.

Dee, D. P., and Coauthors, 2011: The ERA-Interim reanalysis: Configuration and performance of the data assimilation system. Quart. J. Roy. Meteor. Soc., 137, 553-597, https://doi.org/ 10.1002/qj.828.

Ding, Q., E. J. Steig, D. S. Battisti, and J. M. Wallace, 2012: Influence of the tropics on the southern annular mode. J. Climate, 25, 6330-6348, https://doi.org/10.1175/JCLI-D-11-00523.1.

Fogt, R. L., D. H. Bromwich, and K. M. Hines, 2011: Understanding the SAM influence on the South Pacific ENSO teleconnection. Climate Dyn., 36, 1555-1576, https://doi.org/10.1007/s00382-010-0905-0.

Frederiksen, C. S., J. S. Frederiksen, J. M. Sisson, and S. L. Osbrough, 2017: Trends and projections of Southern Hemisphere baroclinicity: The role of external forcing and impact on Australian rainfall. Climate Dyn., 48, 3261-3282, https://doi.org/10.1007/ s00382-016-3263-8.

Frederiksen, J. S., and C. S. Frederiksen, 2007: Interdecadal changes in Southern Hemisphere winter storm track modes. Tellus, 59A, 599-617, https://doi.org/10.1111/j.1600-0870.2007.00264.x.

Gibson, P. B., S. E. Perkins-Kirkpatrick, P. Uotila, A. S. Pepler, and L. V. Alexander, 2017: On the use of self-organizing maps for studying climate extremes. J. Geophys. Res. Atmos., 122, 3891-3903, https://doi.org/10.1002/2016JD026256.

Gillett, N. P., T. D. Kell, and P. D. Jones, 2006: Regional climate impacts of the southern annular mode. Geophys. Res. Lett., 33, L23704, https://doi.org/10.1029/2006GL027721.

Gorodetskaya, I. V., M. Tsukernik, K. Claes, M. F. Ralph, W. D. Neff, and N. P. M. Van Lipzig, 2014: The role of atmospheric rivers in anomalous snow accumulation in East Antarctica. Geophys. Res. Lett., 41, 6199-6206, https://doi.org/10.1002/ 2014GL060881.

Grieger, J., G. C. Leckebusch, C. C. Raible, I. Rudeva, and I. Simmonds, 2018: Subantarctic cyclones identified by 14 tracking methods, and their role for moisture transports into the continent. Tellus, $\mathbf{7 0 A}, 1-18$, https://doi.org/10.1080/ 16000870.2018 .1454808 .

Hendon, H. H., D. W. J. Thompson, and M. C. Wheeler, 2007: Australian rainfall and surface temperature variations associated with the Southern Hemisphere annular mode. J. Climate, 20, 2452-2467, https://doi.org/10.1175/JCLI4134.1.

— E.-P. Lim, J. M. Arblaster, and D. L. T. Anderson, 2014: Causes and predictability of the record wet east Australian spring 2010. Climate Dyn., 42, 1155-1174, https://doi.org/ 10.1007/s00382-013-1700-5.

Hessl, A., K. J. Allen, T. Vance, N. J. Abram, and K. M. Saunders, 2017: Reconstructions of the southern annular mode (SAM) during the last millennium. Prog. Phys. Geogr., 41, 834-849, https://doi.org/10.1177/0309133317743165.

Hewitson, B., and R. G. Crane, 2002: Self-organizing maps: Applications to synoptic climatology. Climate Res., 22, 13-26, https://doi.org/10.3354/cr022013.

Ho, M., A. S. Kiem, and D. C. Verdon-Kidd, 2012: The southern annular mode: A comparison of indices. Hydrol. Earth Syst. Sci., 16, 967-982, https://doi.org/10.5194/hess-16-967-2012.

Hope, P. K., W. Drosdowsky, and N. Nicholls, 2006: Shifts in the synoptic systems influencing southwest Western Australia. Climate Dyn., 26, 751-764, https://doi.org/10.1007/s00382-0060115-y.

Hopkins, L. C., and G. J. Holland, 1997: Australian heavy-rain days and associated East Coast cyclones 1958-92. J. Climate, 10, 621-635, https:// doi.org/10.1175/1520-0442(1997)010<0621:AHRDAA>2.0.CO;2.

Hosking, J. S., R. Fogt, E. R. Thomas, V. Moosavi, T. Phillips, J. Coggins, and D. Reusch, 2017: Accumulation in coastal West Antarctic ice core records and the role of cyclone activity. Geophys. Res. Lett., 44, 9084-9092, https://doi.org/ 10.1002/2017GL074722.

Hoskins, B. J., and D. J. Karoly, 1981: The steady linear response of a spherical atmosphere to thermal and orographic forcing. J. Atmos. Sci., 38, 1179-1196, https://doi.org/10.1175/15200469(1981)038<1179:TSLROA > 2.0.CO;2.

Irving, D., and I. Simmonds, 2015: A novel approach to diagnosing Southern Hemisphere planetary wave activity and its influence on regional climate variability. J. Climate, 28, 9041-9057, https://doi.org/10.1175/JCLI-D-15-0287.1.

- , and - 2016: A new method for identifying the PacificSouth American pattern and its influence on regional climate variability. J. Climate, 29, 6109-6125, https://doi.org/10.1175/ JCLI-D-15-0843.1.

Jiang, N., K. Cheung, K. Luo, P. J. Beggs, and W. Zhou, 2012: On two different objective procedures for classifying synoptic weather types over east Australia. Int. J. Climatol., 32, 14751494, https://doi.org/10.1002/joc.2373.

_ , G. Griffiths, and A. Lorrey, 2013: Influence of large-scale climate modes on daily synoptic weather types over New 
Zealand. Int. J. Climatol., 33, 499-519, https://doi.org/10.1002/ joc.3443.

— K. Luo, P. J. Beggs, K. Cheung, and Y. Scorgie, 2015: Insights into the implementation of synoptic weather-type classification using self-organizing maps: An Australian case study. Int. J. Climatol., 35, 3471-3485, https://doi.org/10.1002/joc.4221.

Jones, D. A., and I. Simmonds, 1994: A climatology of Southern Hemisphere anticyclones. Climate Dyn., 10, 333-348, https:// doi.org/10.1007/BF00228031.

Kalnay, E., and Coauthors, 1996: The NCEP/NCAR 40-Year Reanalysis Project. Bull. Amer. Meteor. Soc., 77, 437-471, https://doi.org/10.1175/ 1520-0477(1996)077<0437:TNYRP $>2$ 2.0.CO;2.

Karoly, D. J., 1990: The role of transient eddies in low-frequency zonal variations of the Southern Hemisphere circulation. Tellus, 42A, 41-50, https://doi.org/10.3402/tellusa.v42i1.11858.

Keable, M., I. Simmonds, and K. Keay, 2002: Distribution and temporal variability of $500 \mathrm{hPa}$ cyclone characteristics in the Southern Hemisphere. Int. J. Climatol., 22, 131-150, https:// doi.org/10.1002/joc.728.

Kidson, J. W., 2000: An analysis of New Zealand synoptic types and their use in defining weather regimes. Int. J. Climatol., 20, 299316, https://doi.org/10.1002/(SICI)1097-0088(20000315)20: 3<299::AID-JOC474>3.0.CO;2-B.

Kidston, J., J. A. Renwick, and J. McGregor, 2009: Hemisphericscale seasonality of the southern annular mode and impacts on the climate of New Zealand. J. Climate, 22, 4759-4770, https:// doi.org/10.1175/2009JCLI2640.1.

Kiem, A. S., and D. C. Verdon-Kidd, 2010: Towards understanding hydroclimatic change in Victoria, Australia-Preliminary insights into the "Big Dry." Hydrol. Earth Syst. Sci., 14, 433-445, https://doi.org/10.5194/hess-14-433-2010.

- T. R. Vance, C. R. Tozer, J. L. Roberts, R. Dalla Pozza, J. Vitkovsky, K. Smolders, and M. A. J. Curran, 2020: Learning from the past-Using palaeoclimate data to better understand and manage drought in South East Queensland (SEQ), Australia. J. Hydrol. Reg. Stud., 29, 100686, https:// doi.org/10.1016/j.ejrh.2020.100686.

King, J. C., and J. Turner, 1997: Antarctic Meteorology and Climatology. Cambridge University Press, $422 \mathrm{pp}$.

L'Heureux, M. L., and D. W. J. Thompson, 2006: Observed relationships between the El Niño-Southern Oscillation and the extratropical zonal-mean circulation. J. Climate, 19, 276-287, https://doi.org/10.1175/JCLI3617.1.

Lim, E.-P., H. H. Hendon, and H. Rashid, 2013: Seasonal predictability of the southern annular mode due to its association with ENSO. J. Climate, 26, 8037-8054, https://doi.org/10.1175/ JCLI-D-13-00006.1.

- — - and D. W. J. Thompson, 2018: Seasonal evolution of stratosphere-troposphere coupling in the Southern Hemisphere and implications for the predictability of surface climate. J. Geophys. Res. Atmos., 123, 12 002-12 016, https://doi.org/ 10.1029/2018JD029321.

Liu, P., and Coauthors, 2018: Climatology of tracked persistent maxima of 500-hPa geopotential height. Climate Dyn., 51, 701-717, https://doi.org/10.1007/s00382-017-3950-0.

Lynch, A., P. Uotila, and J. J. Cassano, 2006: Changes in synoptic weather patterns in the polar regions in the twentieth and twenty-first centuries, part 2: Antarctic. Int. J. Climatol., 26, 1181-1199, https://doi.org/10.1002/joc.1305.

Marshall, G. J., 2003: Trends in the southern annular mode from observations and reanalyses. J. Climate, 16, 4134-4143, https:// doi.org/10.1175/1520-0442(2003)016<4134:TITSAM >2. $0 . \mathrm{CO} ; 2$.
_ , and D. W. J. Thompson, 2016: The signatures of large-scale patterns of atmospheric variability in Antarctic surface temperatures. J. Geophys. Res. Atmos., 121, 3276-3289, https:// doi.org/10.1002/2015JD024665.

, and M. R. van den Broeke, 2017: The signature of Southern Hemisphere atmospheric circulation patterns in Antarctic precipitation. Geophys. Res. Lett., 44,11 580-11589, https://doi.org/10.1002/2017GL075998.

Massom, R. A., M. J. Pook, J. C. Comiso, N. Adams, J. Turner, T. Lachlan-Cope, and T. T. Gibson, 2004: Precipitation over the interior East Antarctic ice sheet related to midlatitude blocking-high activity. J. Climate, 17, 1914-1928, https:// doi.org/10.1175/1520-0442(2004)017<1914:POTIEA >2.0. $\mathrm{CO} ; 2$.

McIntosh, P. C., and H. H. Hendon, 2018: Understanding Rossby wave trains forced by the Indian Ocean dipole. Climate Dyn., 50, 2783-2798, https://doi.org/10.1007/s00382-017-3771-1.

McMorrow, A., T. D. van Ommen, V. Morgan, and M. A. J. Curran, 2004: Ultra-high-resolution seasonality of trace-ion species and oxygen isotope ratios in Antarctic firn over four annual cycles. Ann. Glaciol., 39, 34-40, https://doi.org/10.3189/ 172756404781814609.

McPhaden, M. J., S. E. Zebiak, and M. H. Glantz, 2006: ENSO as an integrating concept in Earth science. Science, 314, 17401745, https://doi.org/10.1126/science.1132588.

Murphy, B. F., and B. Timbal, 2008: A review of recent climate variability and climate change in southeastern Australia. Int. J. Climatol., 28, 859-879, https://doi.org/10.1002/joc.1627.

Nguyen, H., C. Lucas, A. Evans, B. Timbal, and L. Hanson, 2015: Expansion of the Southern Hemisphere Hadley cell in response to greenhouse gas forcing. J. Climate, 28, 8067-8077, https://doi.org/10.1175/JCLI-D-15-0139.1.

Peng, S., and J. S. Whitaker, 1999: Mechanisms determining the atmospheric response to midlatitude SST anomalies. J. Climate, 12, 1393-1408, https://doi.org/10.1175/15200442(1999)012<1393:MDTART > 2.0.CO;2.

Pepler, A., A. Dowdy, and P. Hope, 2019a: A global climatology of surface anticyclones, their variability, associated drivers and long-term trends. Climate Dyn., 52, 5397-5412, https://doi.org/ 10.1007/s00382-018-4451-5.

$\longrightarrow$, P. Hope, and A. Dowdy, 2019b: Long-term changes in southern Australian anticyclones and their impacts. Climate Dyn., 53, 4701-4714, https://doi.org/10.1007/s00382-019-04819-9.

Pepler, A. S., A. Di Luca, and J. P. Evans, 2018: Independently assessing the representation of midlatitude cyclones in highresolution reanalyses using satellite observed winds. Int. J. Climatol., 38, 1314-1327, https://doi.org/10.1002/joc.5245.

Pezza, A. B., and T. Ambrizzi, 2003: Variability of Southern Hemisphere cyclone and anticyclone behavior: Further analysis. J. Climate, 16, 1075-1083, https://doi.org/10.1175/15200442(2003)016<1075:VOSHCA $>2.0$.CO;2.

- - T. Durrant, I. Simmonds, and I. Smith, 2008: Southern Hemisphere synoptic behavior in extreme phases of SAM, ENSO, sea ice extent, and southern Australia rainfall. J. Climate, 21, 5566-5584, https://doi.org/ 10.1175/2008JCLI2128.1.

- H. A. Rashid, and I. Simmonds, 2012: Climate links and recent extremes in Antarctic sea ice, high-latitude cyclones, southern annular mode and ENSO. Climate Dyn., 38, 57-73, https://doi.org/10.1007/s00382-011-1044-y.

Pohl, B., and N. Fauchereau, 2012: The southern annular mode seen through weather regimes. J. Climate, 25, 3336-3354, https://doi.org/10.1175/JCLI-D-11-00160.1. 
Pook, M., 1994: Atmosphere blocking in the Australasian region in the Southern Hemisphere winter. Ph.D. thesis, Institute of Antarctic and Southern Ocean Studies, University of Tasmania, $168 \mathrm{pp}$.

— during SOP-1 of the FROST Project. Aust. Meteor. Mag., 48, 51-60.

— , P. C. McIntosh, and G. A. Meyers, 2006: The synoptic decomposition of cool-season rainfall in the southeastern Australian cropping region. J. Appl. Meteor. Climatol., 45, 1156-1170, https://doi.org/10.1175/JAM2394.1.

— J J. S. Risbey, and P. C. McIntosh, 2012: The synoptic climatology of cool-season rainfall in the central wheatbelt of western Australia. Mon. Wea. Rev., 140, 28-43, https://doi.org/ 10.1175/MWR-D-11-00048.1.

Purich, A., and M. H. England, 2019: Tropical teleconnections to Antarctic sea ice during austral spring 2016 in coupled pacemaker experiments. Geophys. Res. Lett., 46, 6848-6858, https://doi.org/10.1029/2019GL082671.

Qi, L., L. M. Leslie, and S. X. Zhao, 1999: Cut-off low pressure systems over southern Australia: Climatology and case study. Int. J. Climatol., 19, 1633-1649, https://doi.org/10.1002/(SICI) 1097-0088(199912)19:15<1633::AID-JOC445>3.0.CO;2-0.

Reijmer, C. H., M. R. Broeke, and M. P. Scheele, 2002: Air parcel trajectories and snowfall related to five deep drilling locations in Antarctica based on the ERA-15 dataset. J. Climate, 15, 1957-1968, https://doi.org/10.1175/1520-0442(2002)015<1957: APTASR $>2.0 . \mathrm{CO} ; 2$.

Renwick, J. A., 2005: Persistent positive anomalies in the Southern Hemisphere circulation. Mon. Wea. Rev., 133, 977-988, https:// doi.org/10.1175/MWR2900.1.

Reusch, D. B., 2010: Nonlinear climatology and paleoclimatology: Capturing patterns of variability and change with self-organizing maps. Phys. Chem. Earth, 35, 329-340, https://doi.org/10.1016/ j.pce.2009.09.001.

— B. B. Hewitson, and R. B. Alley, 2005: Towards ice-corebased synoptic reconstructions of West Antarctic climate with artificial neural networks. Int. J. Climatol., 25, 581-610, https:// doi.org/10.1002/joc.1143.

Risbey, J. S., M. J. Pook, P. C. McIntosh, M. C. Wheeler, and H. H. Hendon, 2009: On the remote drivers of rainfall variability in Australia. Mon. Wea. Rev., 137, 3233-3253, https://doi.org/ 10.1175/2009MWR2861.1.

Roberts, J., and Coauthors, 2015: A 2000-year annual record of snow accumulation rates for Law Dome, East Antarctica. Climate Past, 11, 697-707, https://doi.org/10.5194/cp-11-697-2015.

Rohrer, M., O. Martius, C. C. Raible, and S. Brönnimann, 2020: Sensitivity of blocks and cyclones in ERA5 to spatial resolution and definition. Geophys. Res. Lett., 47, e2019GL085582, https://doi.org/10.1029/2019GL085582.

Rudeva, I., and I. Simmonds, 2015: Variability and trends of global atmospheric frontal activity and links with large-scale modes of variability. J. Climate, 28, 3311-3330, https://doi.org/ 10.1175/JCLI-D-14-00458.1.

,-- D. Crock, and G. Boschat, 2019: Midlatitude fronts and variability in the Southern Hemisphere tropical width. J. Climate, 32, 8243-8260, https://doi.org/10.1175/JCLI-D18-0782.1.

Saji, N. H., B. N. Goswami, P. N. Vinayachandran, and T. Yamagata, 1999: A dipole mode in the tropical Indian Ocean. Nature, 401, 360-363, https://doi.org/10.1038/43854.

Scarchilli, C., M. Frezzotti, and P. M. Ruti, 2011: Snow precipitation at four ice core sites in East Antarctica: Provenance, seasonality and blocking factors. Climate Dyn., 37, 2107-2125, https://doi.org/10.1007/s00382-010-0946-4.

Schlosser, E., and Coauthors, 2017: The influence of the synoptic regime on stable water isotopes in precipitation at Dome $\mathrm{C}$, East Antarctica. Cryosphere, 11, 2345-2361, https://doi.org/ 10.5194/tc-11-2345-2017.

Sen Gupta, A., and M. H. England, 2006: Coupled oceanatmosphere-ice response to variations in the southern annular mode. J. Climate, 19, 4457-4486, https://doi.org/10.1175/ JCLI3843.1.

Servettaz, A. P. M., and Coauthors, 2020: Snowfall and water stable isotope variability in East Antarctica controlled by warm synoptic events. J. Geophys. Res. Atmos., 125, e2020JD032863, https://doi.org/10.1029/2020JD032863.

Simmonds, I., 2015: Comparing and contrasting the behaviour of Arctic and Antarctic sea ice over the 35 year period 1979-2013. Ann. Glaciol., 56, 18-28, https://doi.org/10.3189/2015AoG69A909.

—_ and K. Keay, 2000: Variability of Southern Hemisphere extratropical cyclone behavior, 1958-97. J. Climate, 13, 550-561, https://doi.org/10.1175/1520-0442(2000)013<0550:VOSHEC >2. $0 . \mathrm{CO} ; 2$.

, - — and E.-P. Lim, 2003: Synoptic activity in the seas around Antarctica. Mon. Wea. Rev., 131, 272-288, https://doi.org/ 10.1175/1520-0493(2003)131<0272:SAITSA > 2.0.CO;2.

Sinclair, M. R., 1996: A climatology of anticyclones and blocking for the Southern Hemisphere. Mon. Wea. Rev., 124, 245-264, https://doi.org/10.1175/1520-0493(1996)124<0245:ACOAAB >2. $0 . \mathrm{CO} ; 2$.

Sinclair, V. A., and H. F. Dacre, 2019: Which extratropical cyclones contribute most to the transport of moisture in the Southern Hemisphere? J. Geophys. Res., 124, 2525-2545, https://doi.org/ 10.1029/2018JD028766.

Spensberger, C., M. J. Reeder, T. Spengler, and M. Patterson, 2019: The connection between the southern annular mode and a feature-based perspective on Southern Hemisphere midlatitude winter variability. J. Climate, 33, 115-129, https://doi.org/ 10.1175/JCLI-D-19-0224.1.

Thompson, D. W. J., and J. M. Wallace, 2000: Annular modes in the extratropical circulation. Part I: Month-to-month variability. J. Climate, 13, 1000-1016, https://doi.org/10.1175/15200442(2000)013<1000:AMITEC>2.0.CO;2.

Tozer, C. R., A. S. Kiem, T. R. Vance, J. L. Roberts, M. A. J. Curran, and A. D. Moy, 2018: Reconstructing pre-instrumental streamflow in Eastern Australia using a water balance approach. J. Hydrol., 558, 632-646, https://doi.org/10.1016/j.jhydrol.2018.01.064.

Troup, A. J., 1965: The 'southern oscillation.' Quart. J. Roy. Meteor. Soc., 91, 490-506, https://doi.org/10.1002/qj.49709139009.

Turner, J., 2004: The El Niño-southern oscillation and Antarctica. Int. J. Climatol., 24, 1-31, https://doi.org/10.1002/joc.965.

— J. S. Hosking, T. J. Bracegirdle, T. Phillips, and G. J. Marshall, 2017: Variability and trends in the Southern Hemisphere high latitude, quasi-stationary planetary waves. Int. J. Climatol., 37, 2325-2336, https://doi.org/10.1002/joc.4848.

— itation events in Antarctic snowfall variability. Geophys. Res. Lett., 46, 3502-3511, https://doi.org/10.1029/2018GL081517.

Uotila, P., T. Vihma, A. B. Pezza, I. Simmonds, K. Keay, and A. H. Lynch, 2011: Relationships between Antarctic cyclones and surface conditions as derived from high-resolution numerical weather prediction data. J. Geophys. Res., 116, D07109, https://doi.org/10.1029/2010JD015358.

Vance, T. R., T. D. van Ommen, M. A. J. Curran, C. T. Plummer, and A. D. Moy, 2013: A millennial proxy record of ENSO and 
eastern Australian rainfall from the Law Dome ice core, east Antarctica. J. Climate, 26, 710-725, https://doi.org/10.1175/ JCLI-D-12-00003.1.

, J. L. Roberts, C. T. Plummer, A. S. Kiem, and T. D. van Ommen, 2015: Interdecadal Pacific variability and eastern Australian megadroughts over the last millennium. Geophys. Res. Lett., 42, 129-137, https://doi.org/10.1002/2014GL062447. , and Coauthors, 2016: Optimal site selection for a highresolution ice core record in East Antarctica. Climate Past, 12, 595-610, https://doi.org/10.5194/cp-12-595-2016.

van Ommen, T. D., and V. Morgan, 2010: Snowfall increase in coastal East Antarctica linked with southwest Western Australian drought. Nat. Geosci., 3, 267-272, https://doi.org/10.1038/ngeo761.

Verdon, D. C., and S. W. Franks, 2005: Indian Ocean sea surface temperature variability and winter rainfall: Eastern Australia. Water Resour. Res., 41, W09413, https://doi.org/10.1029/2004WR003845.

Verdon-Kidd, D. C., and A. S. Kiem, 2009: On the relationship between large-scale climate modes and regional synoptic patterns that drive Victorian rainfall. Hydrol. Earth Syst. Sci., 13, 467-479, https://doi.org/10.5194/hess-13-467-2009.

- - - and R. Moran, 2014: Links between the Big Dry in Australia and hemispheric multi-decadal climate variability; implications for water resource management. Hydrol. Earth Syst. Sci., 18, 2235-2256, https://doi.org/10.5194/hess-18-22352014.

Walsh, K. J. E., I. Simmonds, and M. Collier, 2000: Sigma-coordinate calculation of topographically forced baroclinicity around Antarctica. Dyn. Atmos. Oceans, 33, 1-29, https:// doi.org/10.1016/S0377-0265(00)00054-3.

Wang, G., and H. H. Hendon, 2007: Sensitivity of Australian rainfall to inter-El Niño variations. J. Climate, 20, 4211-4226, https://doi.org/10.1175/JCLI4228.1.

-, J. M. Arblaster, E.-P. Lim, S. Abhik, and P. van Rensch, 2019: Compounding tropical and stratospheric forcing of the record low Antarctic sea-ice in 2016. Nat. Commun., 10, 13, https://doi.org/10.1038/s41467-018-07689-7.

Wehrens, R., and J. Kruisselbrink, 2018: Flexible self-organizing maps in Kohonen 3.0. J. Stat. Software, 87, 18, https://doi.org/ 10.18637/jss.v087.i07.

Wille, J. D., V. Favier, A. Dufour, I. V. Gorodetskaya, J. Turner, C. Agosta, and F. Codron, 2019: West Antarctic surface melt triggered by atmospheric rivers. Nat. Geosci., 12, 911-916, https://doi.org/10.1038/s41561-019-0460-1.

Wright, A. D. F., 1974: Blocking action in the Australian region. Bureau of Meteorology Tech. Rep. 10, 29 pp.

Yang, D., J. M. Arblaster, G. A. Meehl, M. H. England, E.-P. Lim, S. Bates, and N. Rosenbloom, 2020: Role of tropical variability in driving decadal shifts in the Southern Hemisphere summertime eddy-driven jet. J. Climate, 33, 5445-5463, https:// doi.org/10.1175/JCLI-D-19-0604.1.

Yuan, X., M. R. Kaplan, and M. A. Cane, 2018: The interconnected global climate system-A review of tropical-polar teleconnections. J. Climate, 31, 5765-5792, https://doi.org/10.1175/ JCLI-D-16-0637.1. 